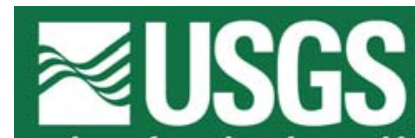

science for a changing world

\title{
Summary and preliminary interpretations of USGS cruise A202HW: Underwater video surveys collected off of Oahu, Molokai, and Maui, Hawaii June- July 2002
}

U.S. DEPARTMENT OF THE INTERIOR

U.S. GEOLOGICAL SURVEY

Open File Report 2005-1244

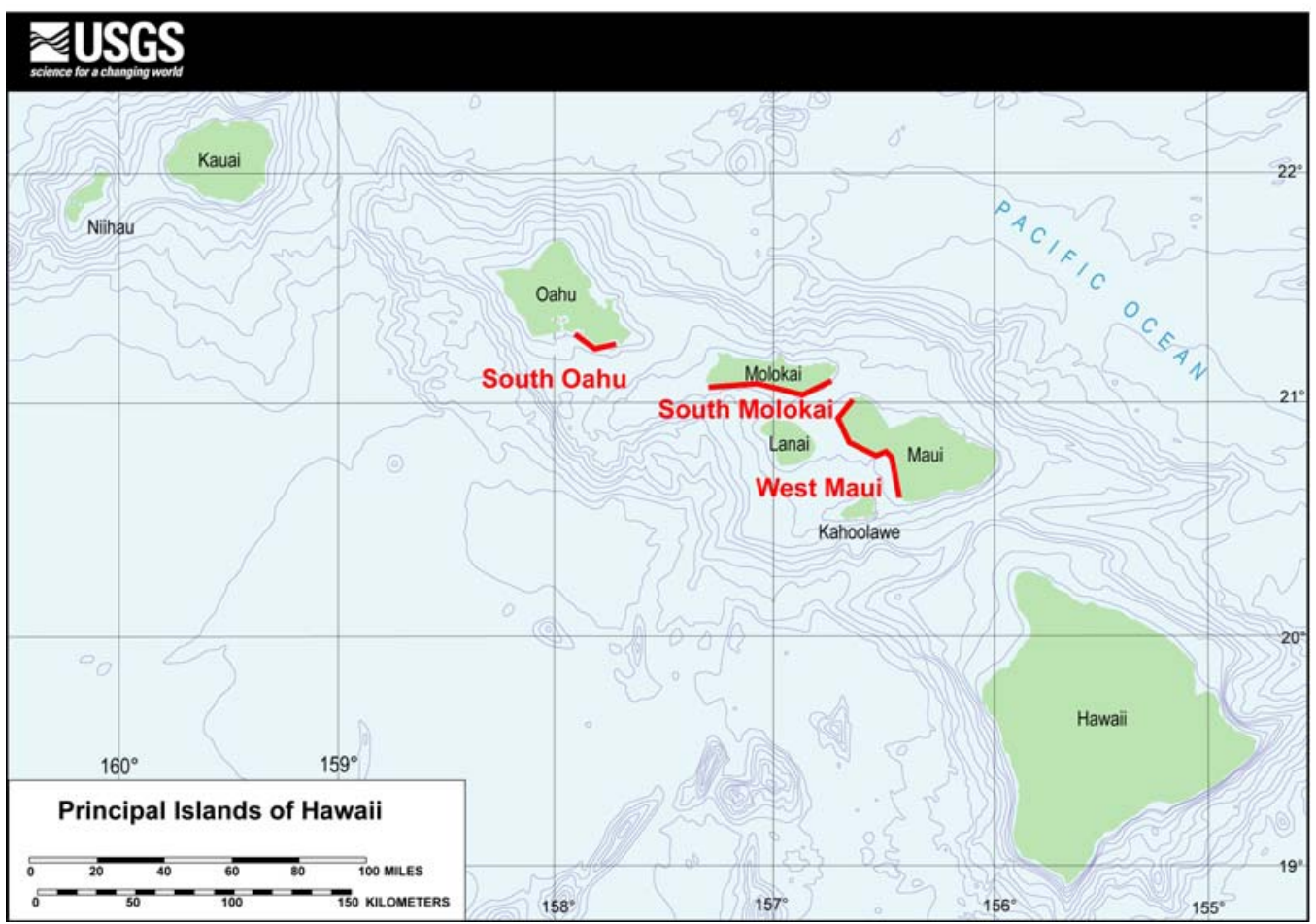





\section{Summary and Preliminary Interpretations of USGS Cruise A-2-02-HW: Underwater Video Surveys Collected Off Of Oahu, Molokai, and Maui, Hawaii June- July 2002}

By Ann Gibbs', Eric Grossman', and Bruce Richmond'

Open File Report 2005-1244

This report is preliminary and has not been reviewed for conformity with U.S. Geological Survey editorial standards and stratigraphic nomenclature. Any use of trade names is for descriptive purposes only and does not imply endorsement by the USGS.

U.S. DEPARTMENT OF THE INTERIOR

U.S. GEOLOGICAL SURVEY

'US Geological Survey, Pacific Science Center, 400 Natural Bridges Drive, Santa Cruz, CA 95060 


\section{ADDITIONAL DIGITAL INFORMATION}

For additional information regarding USGS activity A-2-02-HW, please see:

http://walrus.wr.usgs.gov/infobank/a/a202hw/html/a-2-02-hw.meta.html

For an online PDF version of this report, please see:

http://pubs.usgs.gov/of/2005/1244/

For more information on the U.S. Geological Survey Western Region's Coastal and Marine Geology Team, please see:

http://walrus.wr.usgs.gov

For more information on the U.S. Geological Survey's Coral Reef Project, please see:

http://coralreefs.wr.usgs.gov

\section{DIRECT CONTACT INFORMATION}

Ann Gibbs (agibbs@usgs.gov)

USGS Pacific Science Center

400 Natural Bridges Drive

Santa Cruz, CA 95060

$831-427-4740$

Bruce Richmond (brichmond@usgs.gov)

USGS Pacific Science Center

400 Natural Bridges Drive

Santa Cruz, CA 95060

$831-427-4731$

Eric Grossman (egrossman@usgs.gov)

USGS Pacific Science Center

400 Natural Bridges Drive

Santa Cruz, CA 95060

$831-427-4725$

\section{REPORT REFERENCE}

Gibbs, A., Grossman, E., and Richmond, B., 2005. "Summary and Preliminary Interpretations of USGS Cruise A-2-02-HW: Underwater Video Surveys Collected Off Of Oahu, Molokai, and Maui, Hawaii, June- July 2002” U.S. Geological Survey Open-File Report 2005-1244, 57p. 


\section{TABLE OF CONTENTS}

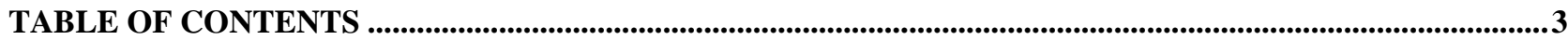

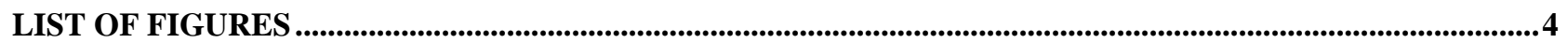

LIST OF TABLES

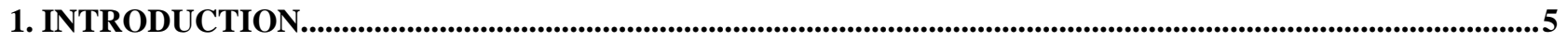

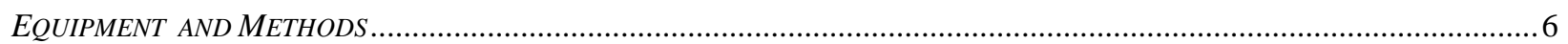

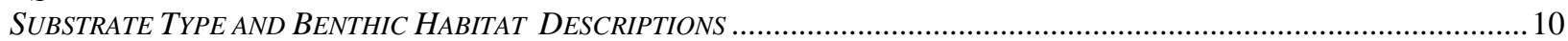

2. SUBSTRATE AND BENTHIC HABITAT MAPPING OF THE SOUTHERN OAHU, HAWAII INSULAR SHELF ............................................................................................................................................................. 15

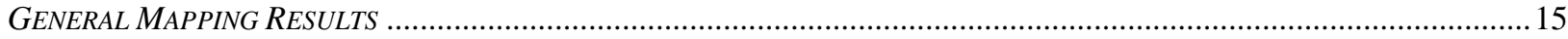

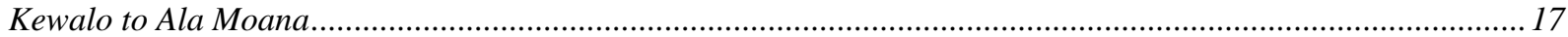

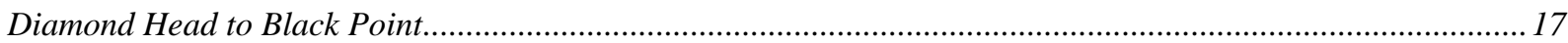

Black Point to Koko Head ............................................................................................................ 18

3. SUBSTRATE AND BENTHIC HABITAT MAPPING OF THE SOUTHERN MOLOKAI, HAWAII

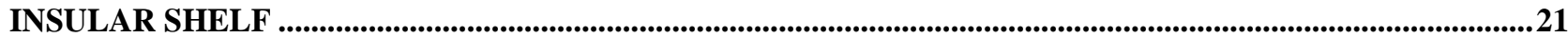

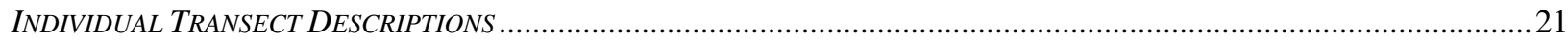

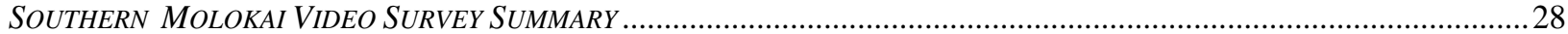

\section{SUBSTRATE AND BENTHIC HABITAT MAPPING OF THE WESTERN MAUI, HAWAII INSULAR}

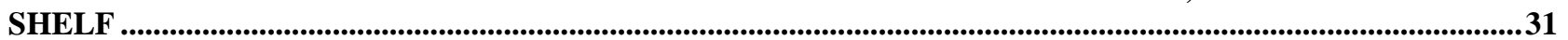

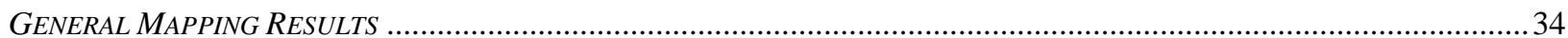

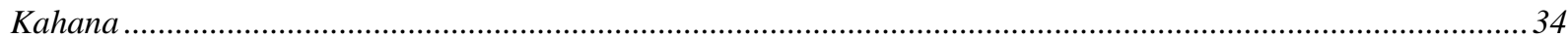

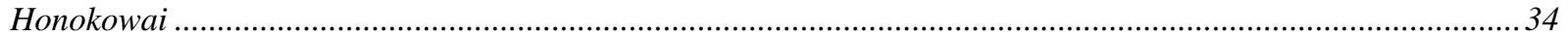

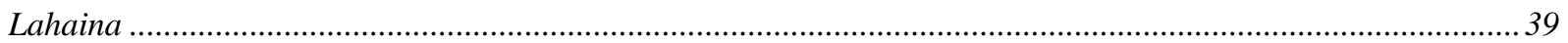

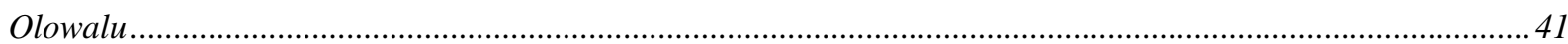

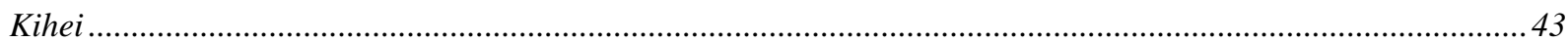

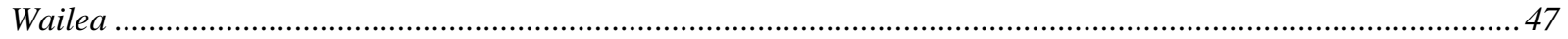

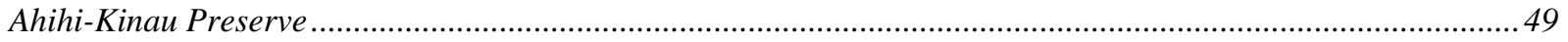

REFERENCES..................................................................................................................................................................5

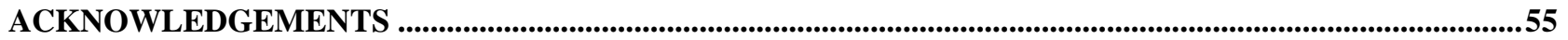

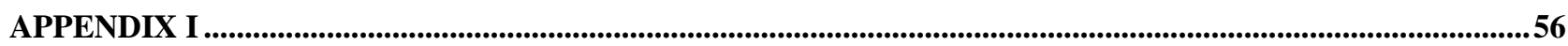

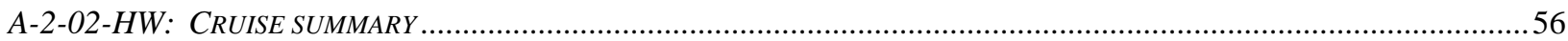

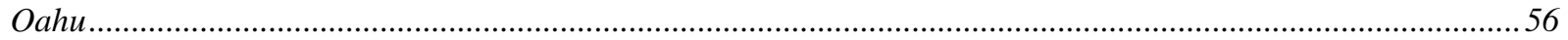

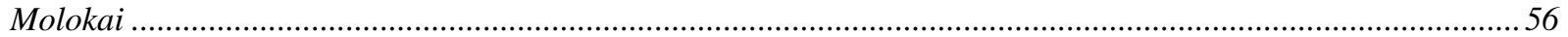

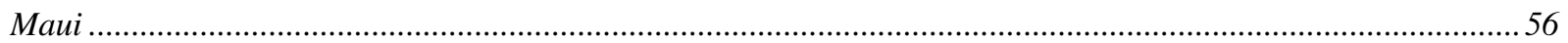

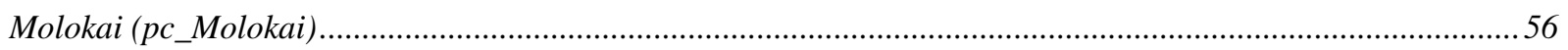

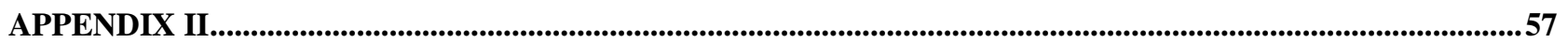

SUMMARY OF DIGITAL 8 VIDEO TAPES, LOCATION, DATES, AND LINES COLLECTED ……………………………...........57 


\section{LIST OF FIGURES}

Figure 1.1 Survey locations for USGS video-mapping cruise A-2-02-HW.

Figure 1.2 Research vessel, AlyceC heading out of the Maalaea Harbor, Maui.

Figure 1.3 USGS video sled containing 2 video cameras, lasers, CT sensor and lights.

Figure 1.4 SeaViewer camera with lights and modular laser.

Figure 1.5 Onboard data acquisition systems.

Figure 1.6 Plot of layback distance as a function of ship speed and camera depth.

Figure 2.1 Study area of substrate and benthic habitat along the south shore of Oahu.

Figure 2.2 Underwater video track line locations of the Molokai study area.

Figure 3.1 Underwater video track line locations of the Molokai study area.

Figure 4.1 Underwater video track line locations of the Maui study area.

Figure 4.2 Location of coral reef and colonized hardbottom on the island of Maui

Figure 4.3 Location of video transects in the Kahana region off Maui.

Figure 4.4 Location of video transects in the Kaanapali region off Maui.

Figure 4.5 Location of video transects off Hanakaoo Point off Maui.

Figure 4.6 Location of video transects in the Lahaina region off Maui.

Figure 4.7 Location of video transects in the Olowalu region off Maui.

Figure 4.8 Location of video transects in the north Kihei region off Maui.

Figure 4.9 Location of video transects in the south Kihei region off Maui.

Figure 4.10 Location of video transects in the Wailea region off Maui.

Figure 4.11 Location of video transects in the Ahihi-Kinau region off Maui.

\section{LIST OF TABLES}

Table 2.1 Underwater video transect summary for southern Oahu.

Table 2.2 UTC, Start (SOL) and end (EOL) locations of survey transects.

Table 3.1 Underwater video transect summary for southern Molokai.

Table 3.2 UTC, Start (SOL) and end (EOL) locations of survey transects.

Table 4.1 Underwater video transect summary for the west coast of Maui.

Table 4.2 UTC, Start (SOL) and end (EOL) locations of survey transects. 


\section{INTRODUCTION}

The insular shelves of the southern coasts of the islands of Oahu and Molokai, and the western coast of Maui in the Hawaiian Archipelago were surveyed using ship-towed video between June 26 and July 11, 2002 as part of USGS-CMG cruise A-2-02-HW (Figure 1.1). The goals of the survey were to collect underwater video of the sea floor to: (1) Characterize substrate type and benthic habitat distribution; and (2) Ground-truth recently-acquired data including bathymetric (SHOALS) lidar, side-scan sonar, seismic reflection, and surface texture and grain size. The underwater video also aids in the interpretation and evaluation of Hawaii's benthic habitat maps produced by NOAA (Coyne et al. 2003) and coral reef distribution monitored by the State of Hawaii (Coral Reef Assessment and Monitoring Program - CRAMP; http://cramp.wcc.hawaii.edu/ ). Additional metadata for this cruise is available at: http://walrus.wr.usgs.gov/infobank/a/a202hw/html/a-2-02hw.meta.html.

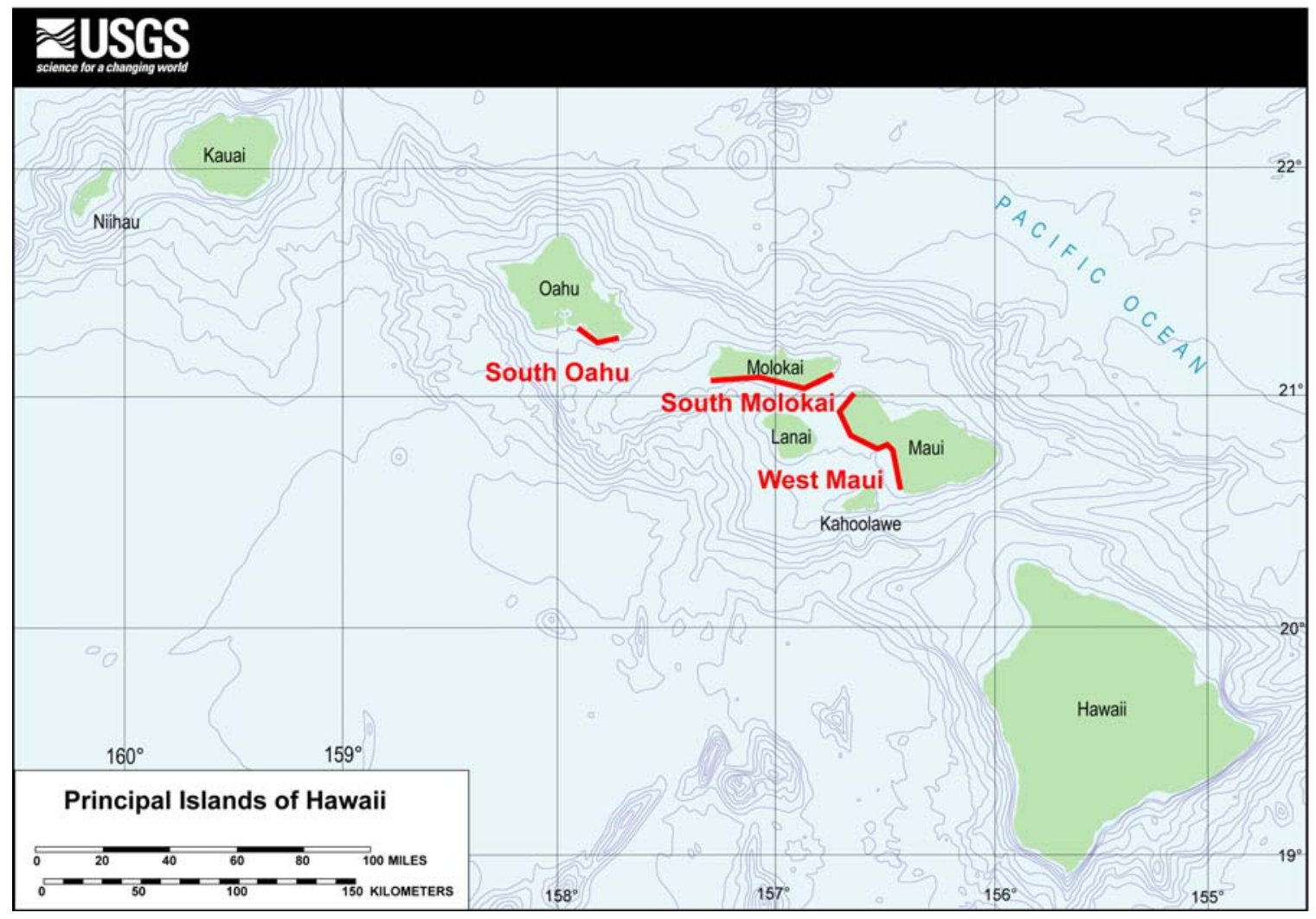

Figure 1.1 Map showing areas surveyed during USGS video mapping cruise A-2-02-HW 


\section{Equipment and Methods}

Underwater video was collected with two different video camera systems towed behind the AlyceC, a 32-ft vessel operated by Cpt. Joe Reich of Molokai (Figure 1.2). The first camera system ("SLED") was fabricated by Hank Chezar (USGS) and included two video cameras - one looking down at nadir, the other slightly ahead along track, HID lights, two lasers, a depth transducer, and a conductivity/temperature (CT) sensor mounted in a robust sled requiring the use of a winch and block (Figure 1.3).

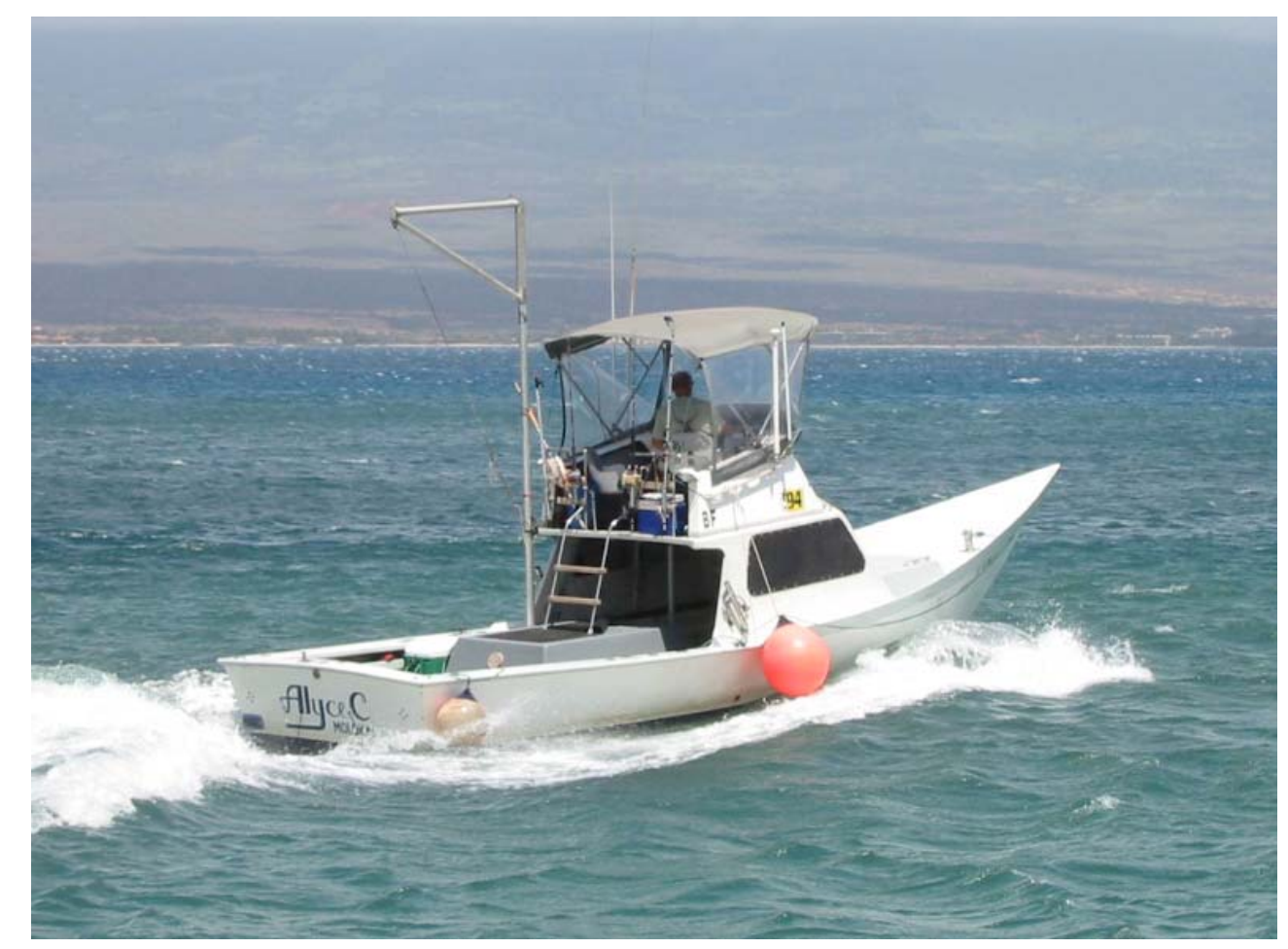

Figure 1.2 Photograph of the research vessel, AlyceC heading out of the Maalaea Harbor, Maui.

The second camera system ("SEAVIEWER") was constructed by Eric Grossman, Gerry Hatcher, and Kevin O'Toole of the USGS by integrating a SeaViewer Camera, LED lights, and batterypowered lasers into a small, hand-held frame (Figure 1.4). Weighing only $12 \mathrm{lbs}$, the SeaViewer was manually deployed and either 'towed' behind the boat or 'dropped' over the side. Live video from both systems was viewed topside on a standard CRT monitor and recorded directly to Digital8 tape and DVD. Time, date, location, and ship speed were overlain on the video using the SeaTrak $^{\mathrm{TM}}$ GPS overlay system developed by SeaViewer Cameras. 


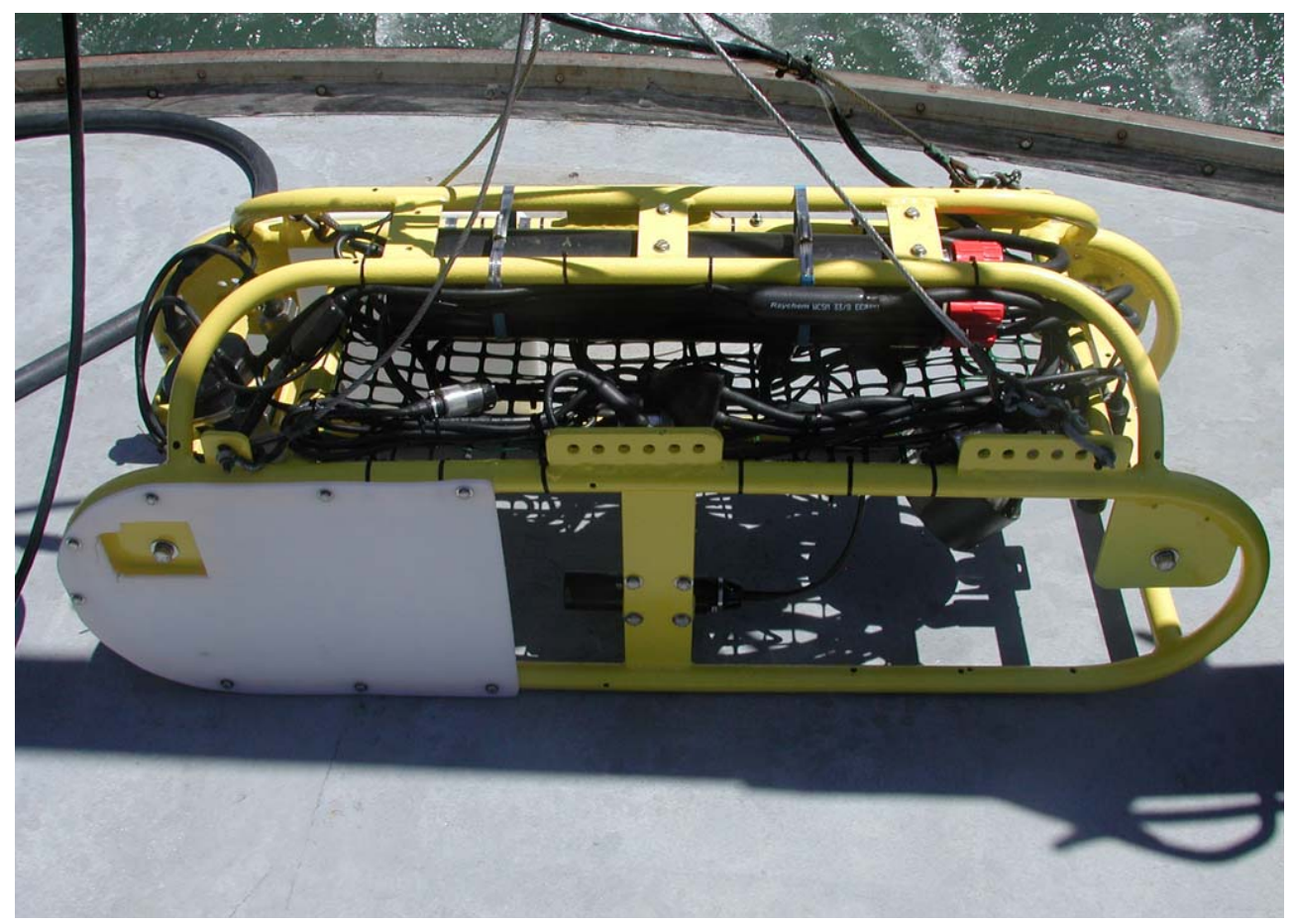

Figure 1.3 Photograph of the USGS video "SLED" camera system

Towed video transects were typically collected from the shallowest depth accessible by the AlyceC onshore to offshore, ending where the benthic environment was either 1) coral free; 2) the seafloor was an unchanging vegetated or non-vegetated sand sheet; 3) where the limit of visibility was reached; or 4) we had deployed maximum cable out (200 feet; $\sim 61 \mathrm{~m}$ ). Transects typically started in water depths of about $10 \mathrm{~m}$ but extended into water depths as great as $40 \mathrm{~m}$. At some locations, shore parallel transects were collected to obtain more detailed information on alongshore variations and to better define transitions in bottom type and/or coral reef environments.

Simultaneous navigation, recording of ship position, and feature annotation was conducted in realtime using Red Hen Systems VMS200 hardware and MediaMapper software on a PC laptop (Figure 1.5). Location data was recorded using a handheld, WAAS-enabled, Garmin GPS76 receiver. The stated horizontal accuracy of the Garmin GSP76 is less than $3 \mathrm{~m}$ when receiving WAAS corrections. The VMS200 transmitted NMEA formatted GPS data at two second intervals to the $1^{\text {st }}$ audio channel of the video tape. A database was simultaneously created by MediaMapper to cross-reference the GPS locations and video time codes. This technique allowed for navigation 
and video to be viewed real-time and the location of features of interest and comments (e.g. Start/End of Lines, substrate types) to be added to the database during data collection. Back in the lab, this technique allowed rapid random access to the original video by selecting locations along the navigation trackline within the MediaMapper software package. Video could be interactively queried and geographically referenced feature annotations added to the data base.

High resolution 1999 and 2000 SHOALS bathymetry (courtesy Jim Gardner, USGS) and georectified 1997 aerial photography (courtesy Chip Fletcher et al., Univ. of Hawaii.; http://www.soest.hawaii.edu/coasts/data/index.html) were used as base map layers in the MediaMapper software. Survey and transect information, starting and ending line positions, environmental conditions, and pertinent features observed on the video were marked and logged real time during the surveys. Eric Grossman provided a running commentary of seafloor substrate type, coral and algal genera/species identifications, coral colony morphologies, and other bottom characteristics. This information was recorded on the primary audio track of the DVD.

It should be noted that all navigation information, including the location of the camera and any features referenced along the video, is the position of the GPS antenna on board the ship and not the real location of the camera in the water. A reasonable estimate of the camera's position behind the ship's GPS (the "layback") was determined during this cruise by manually measuring the distance of the camera behind the GPS over the range of operational ship velocities and depths. Resulting curves of layback distance are shown in Figure 1.6. Positional data in this report were not corrected for layback and thus represent only approximate locations. The layback curves are included here so future users can refer to them in order to determine more accurate positions. 


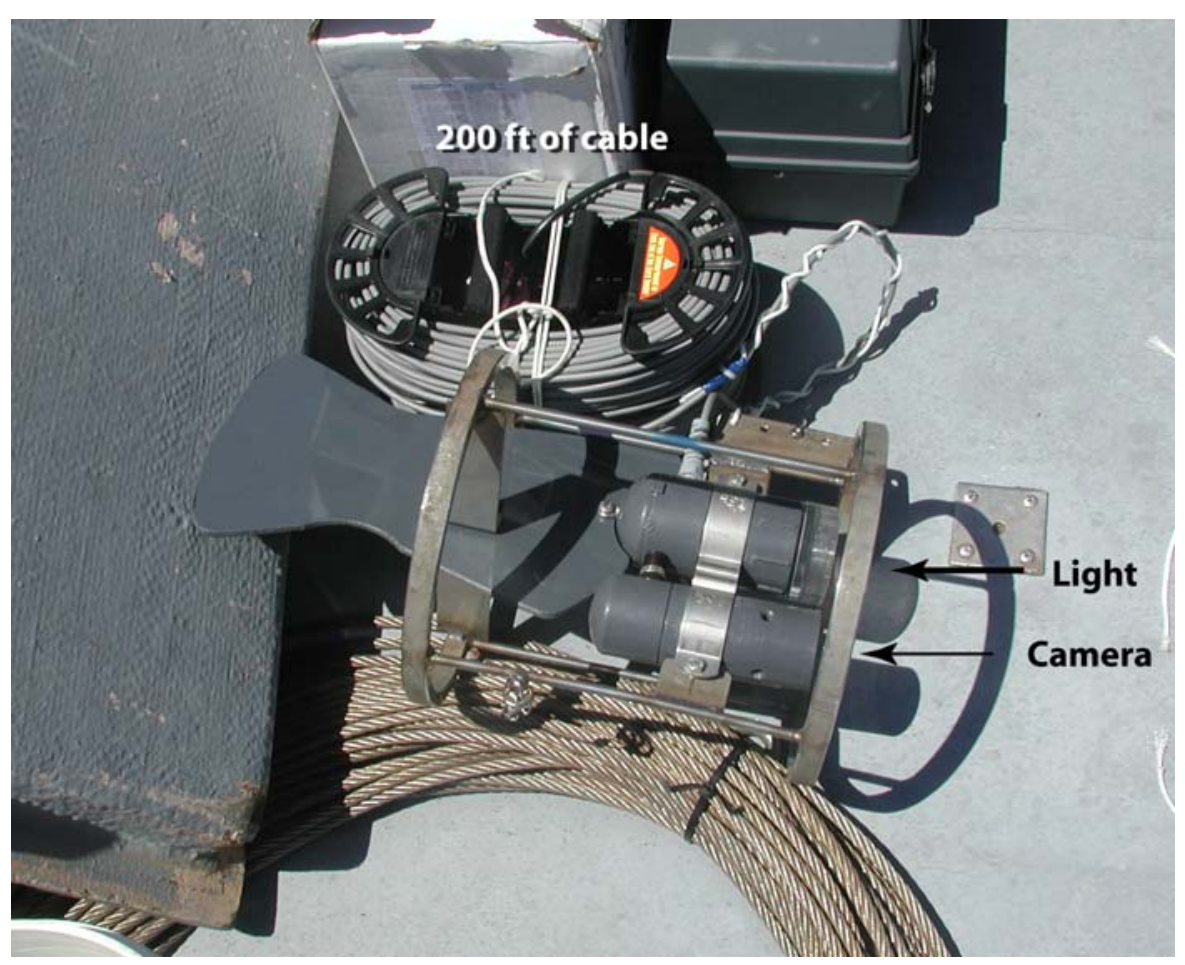

Figure 1.4 Photograph of the SEAVIEWER camera system rigged to collect towed video.

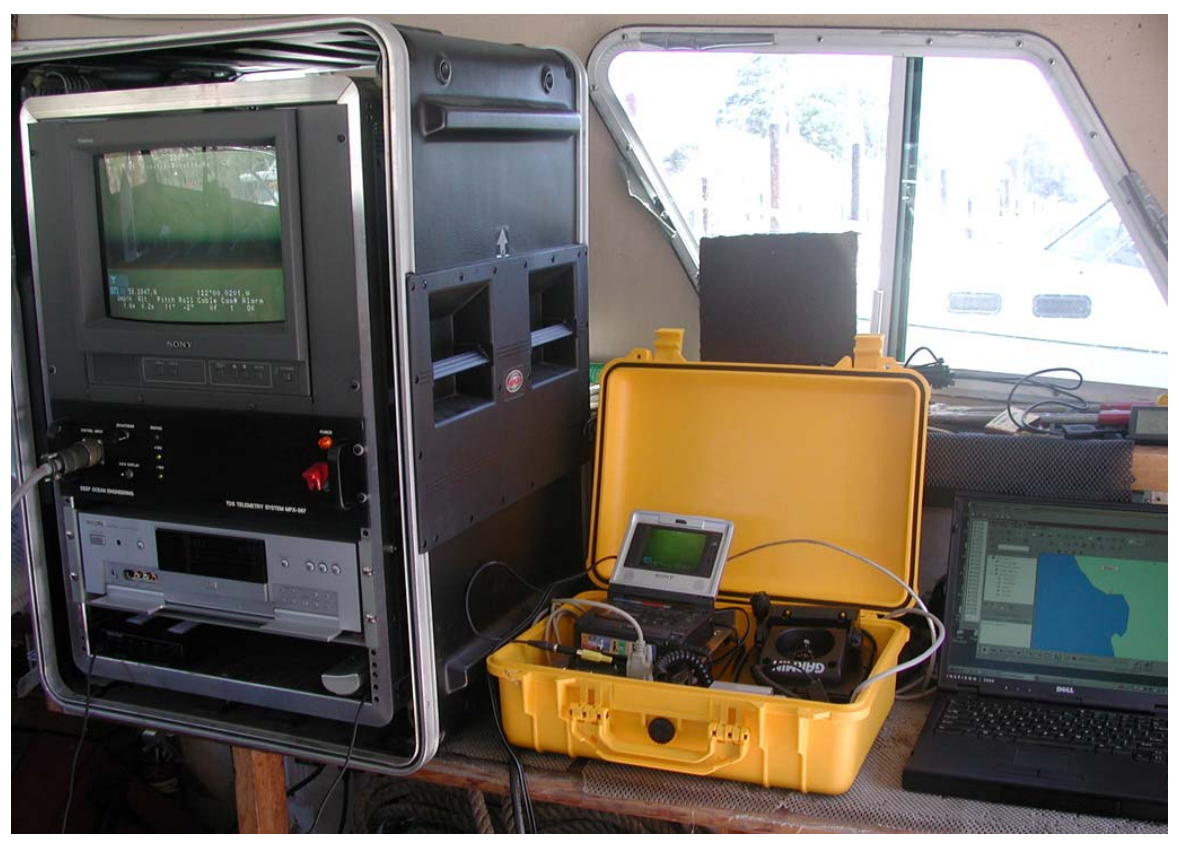

Figure 1.5 Data acquisition for the camera SLED included a DVD recorder, monitor, and text overlay unit housed in ocean-going black case (left). Video from the SEAVIEWER system was recorded on a Digital-8 tape deck (in yellow waterproof box, center) after the. GPS data was burned onto the video image and written to the audio track. A PC Laptop (right) displayed track lines for navigation, recorded incoming GPS position data, and output display topside for captain's navigation. 


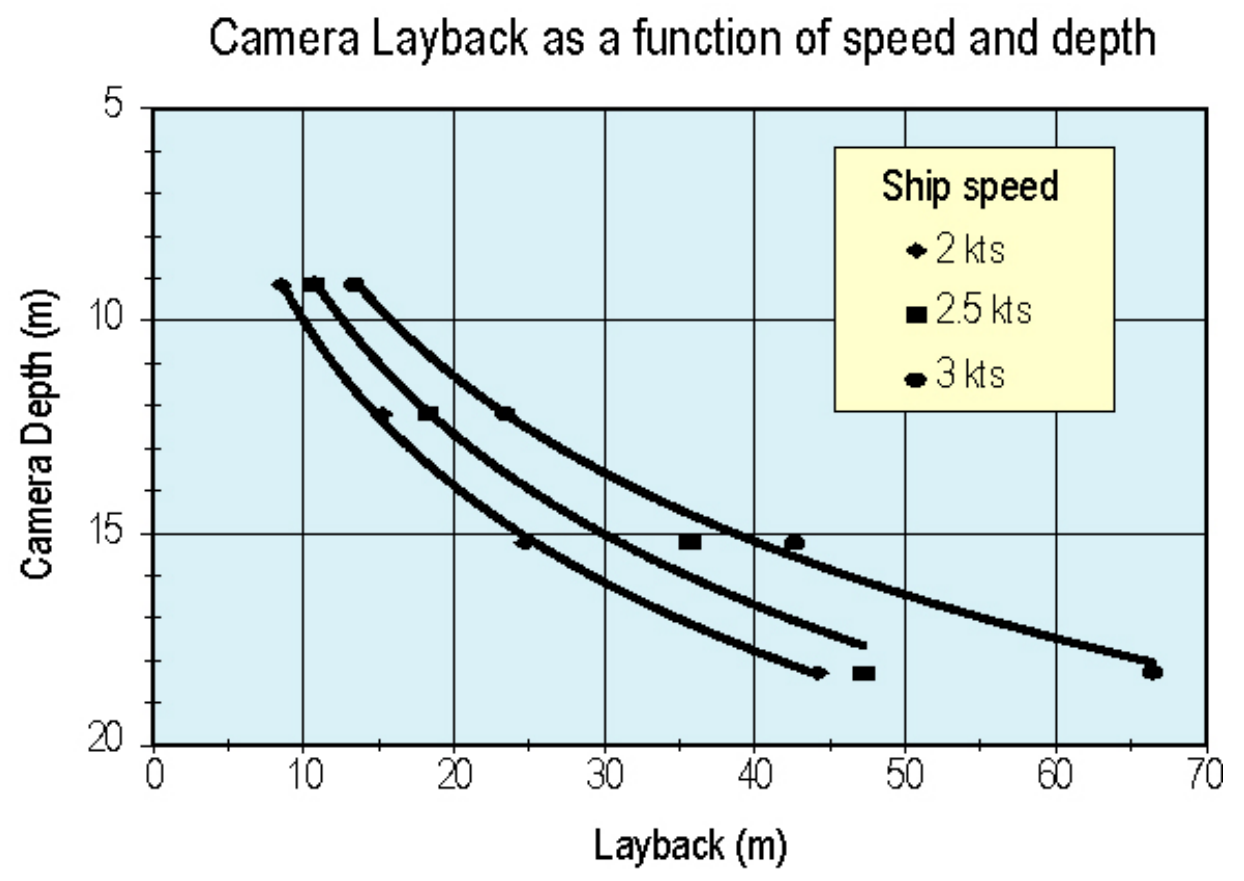

Figure 1.6 Plot of layback distance as a function of ship speed and camera depth.

\section{Substrate Type and Benthic Habitat Descriptions}

Descriptions of substrate and bottom types included in this report are loosely based on the Habitat Classification Scheme developed by NOAA for the Main 8 Hawaiian Islands (Coyne et al., 2003). Our descriptions differ from the NOAA scheme in that only general habitats are described and percent cover within the different categories are not determined. Definitions of the habitats (from Coyne et al., 2003) and representative photos acquired from the video are presented below. 
Unconsolidated sediment-Sand: Coarse sediment typically found in areas exposed to currents or wave energy.

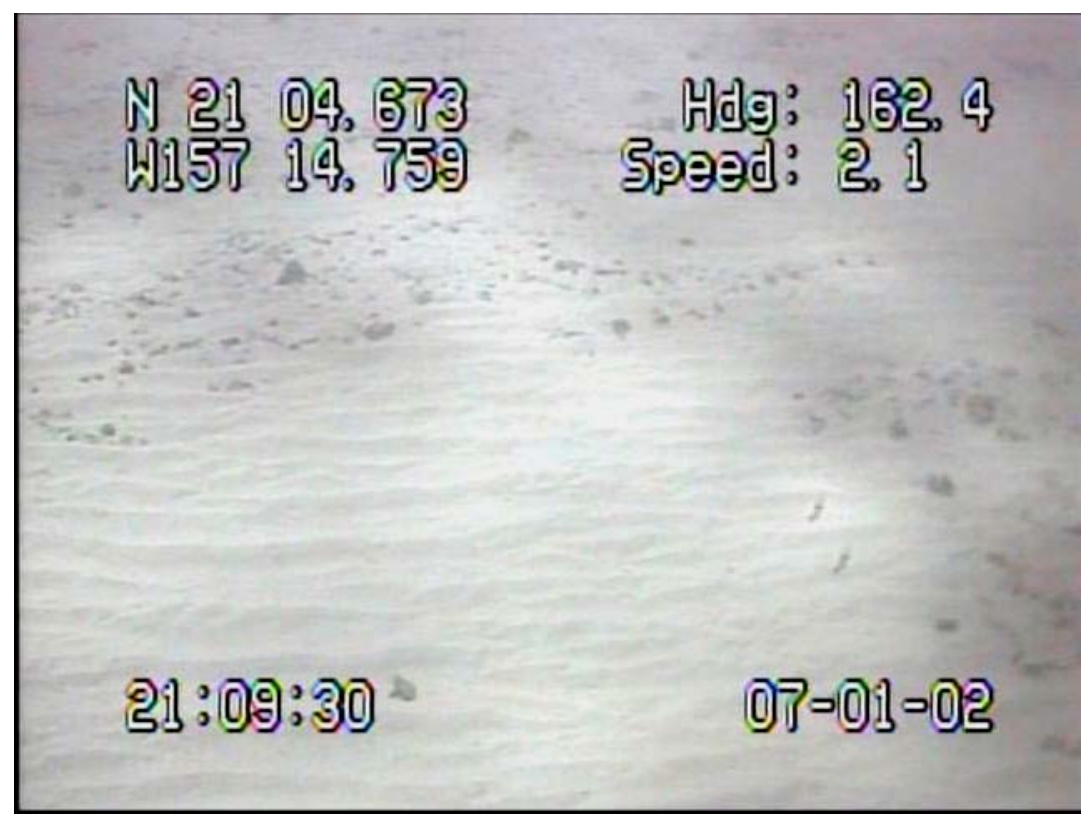

Uncolonized Pavement: Flat, low relief, solid carbonate rock that is often covered by a thin sand veneer. The pavement's surface often has sparse coverage of macroalgae, hard coral, zoanthids, and other sessile invertebrates that does not obscure the underlying surface.

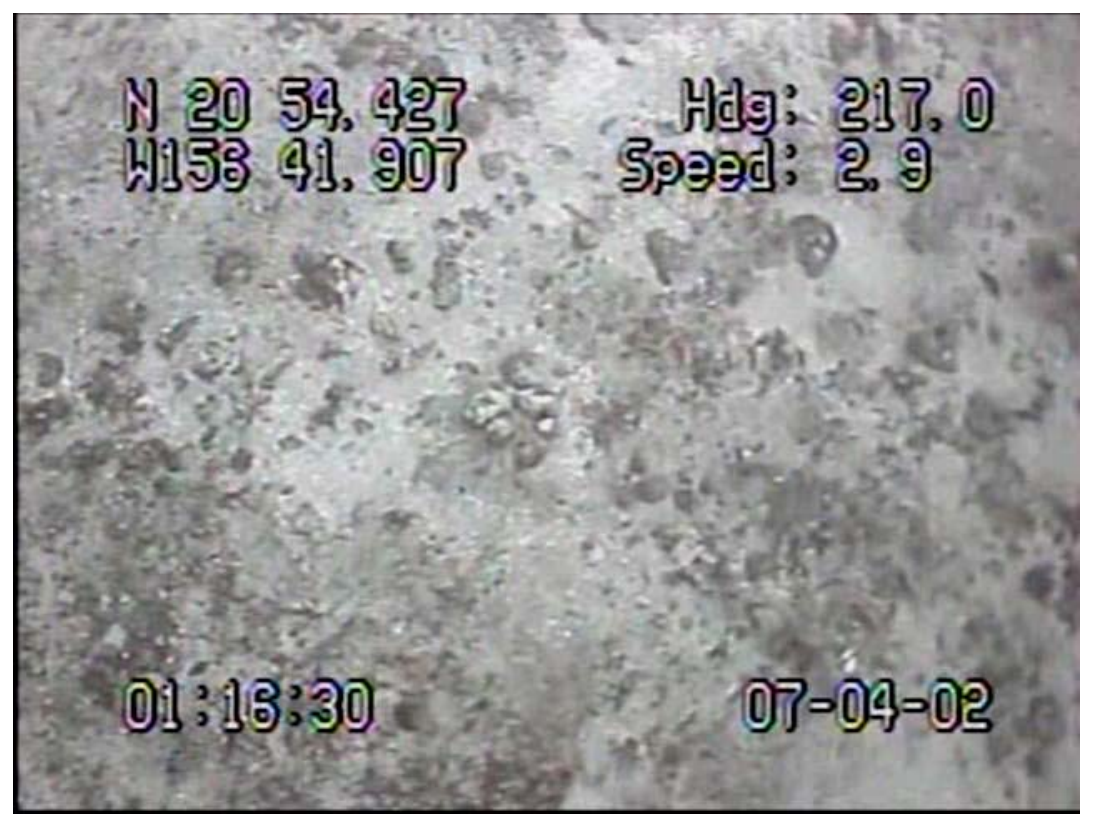


Colonized Pavement: Flat, low-relief, solid carbonate rock with coverage of macroalgae, hard coral, zoanthids, and other sessile invertebrates that are dense enough to begin to obscure the underlying surface.

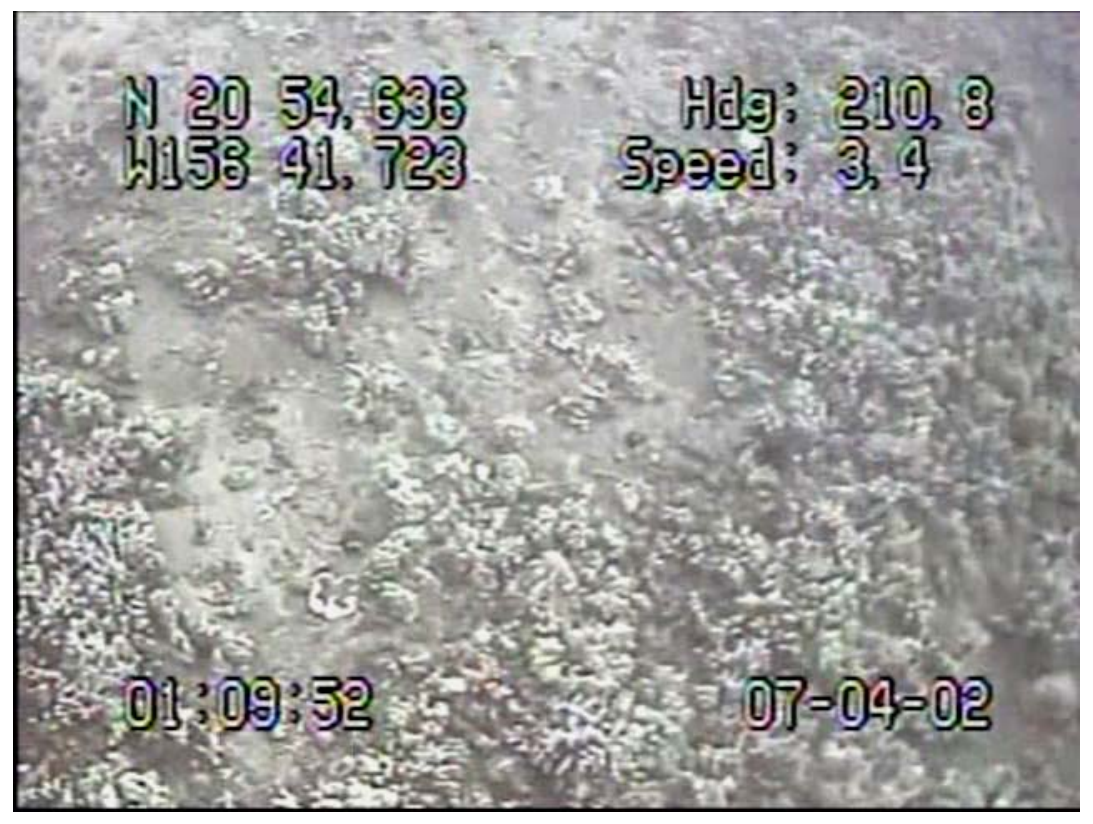

Colonized Volcanic Rock/Boulder: Solid volcanic rock that has coverage of macroalgae, hard coral, zoanthids, and other sessile invertebrates that begins to obscure the underlying surface.

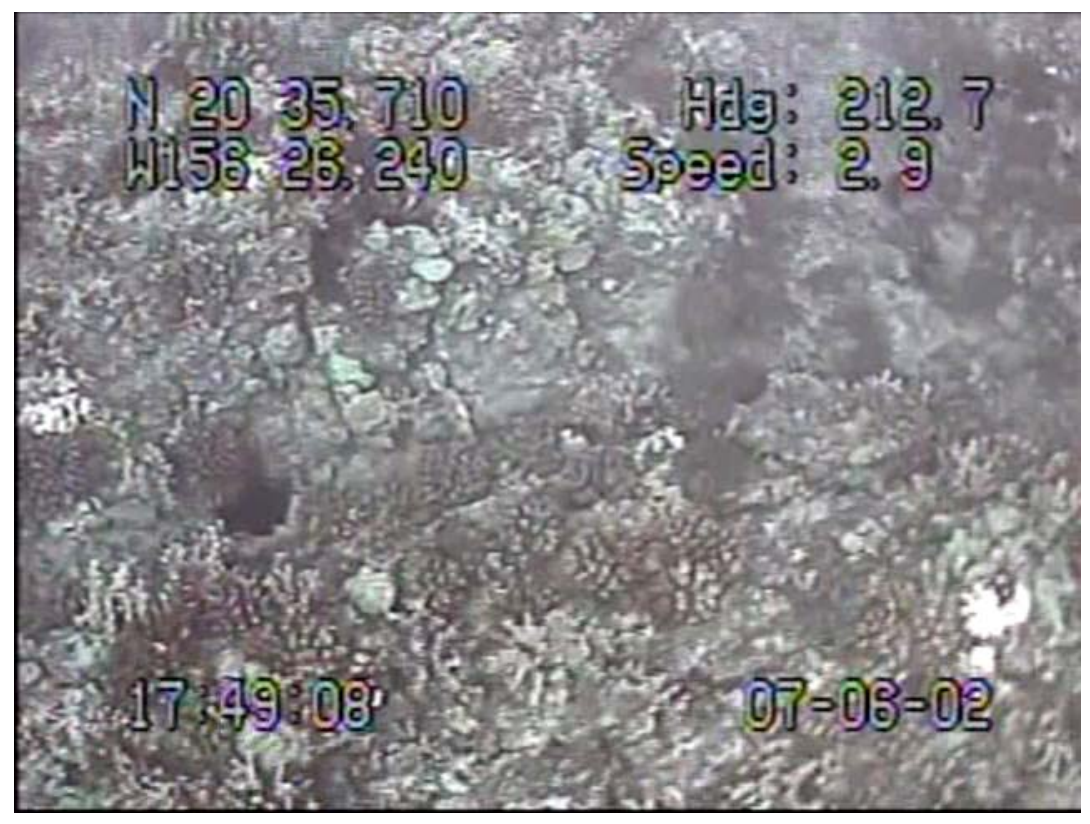


Aggregated Coral: Coral-dominated formations with high relief and structural complexity. Often serve the same role as linear reef in fringing reef systems where the reef crest is relatively unorganized.

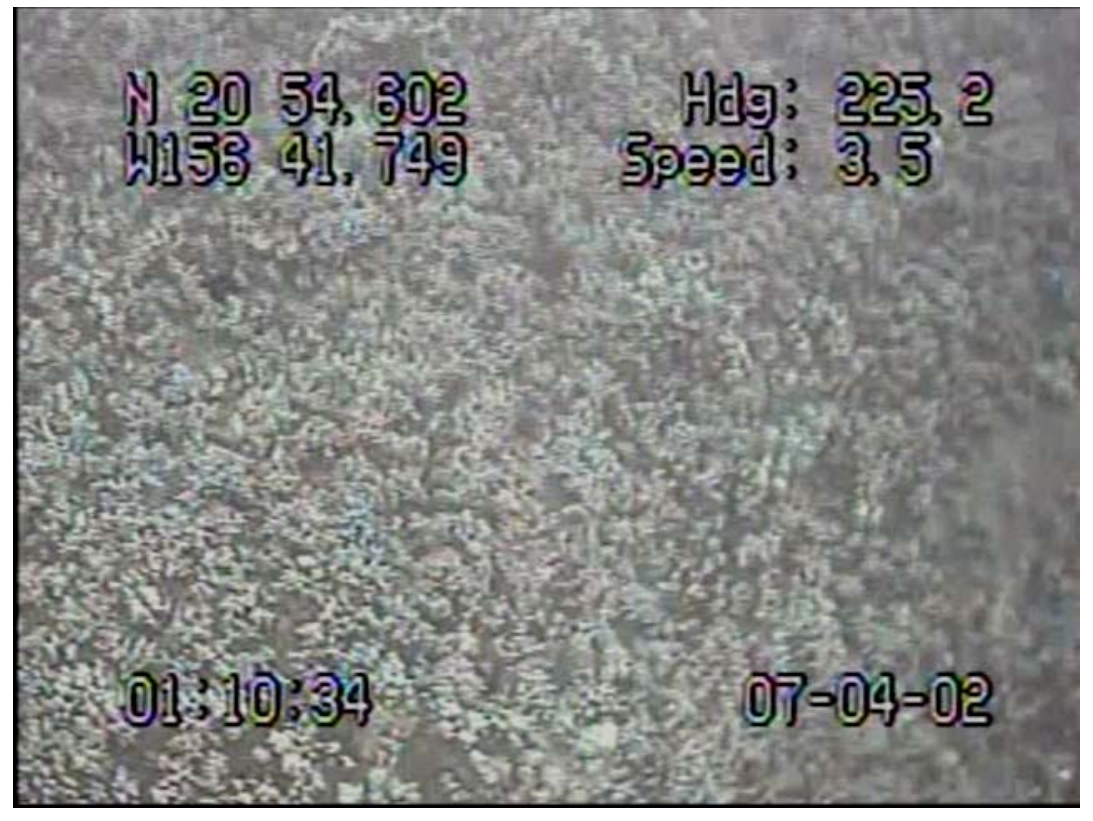

Spur and Groove: Habitat having alternating sand and coral formations that are oriented perpendicular to the shore or bank/shelf escarpment. The coral formations (spurs) of this feature typically have a high vertical relief relative to pavement with sand channels and are separated from each other by 1-5 meters of sand or bare hardbottom (grooves), although the height and width of these elements may vary considerably. This habitat type typically occurs in the fore reef or bank/shelf escarpment zone.

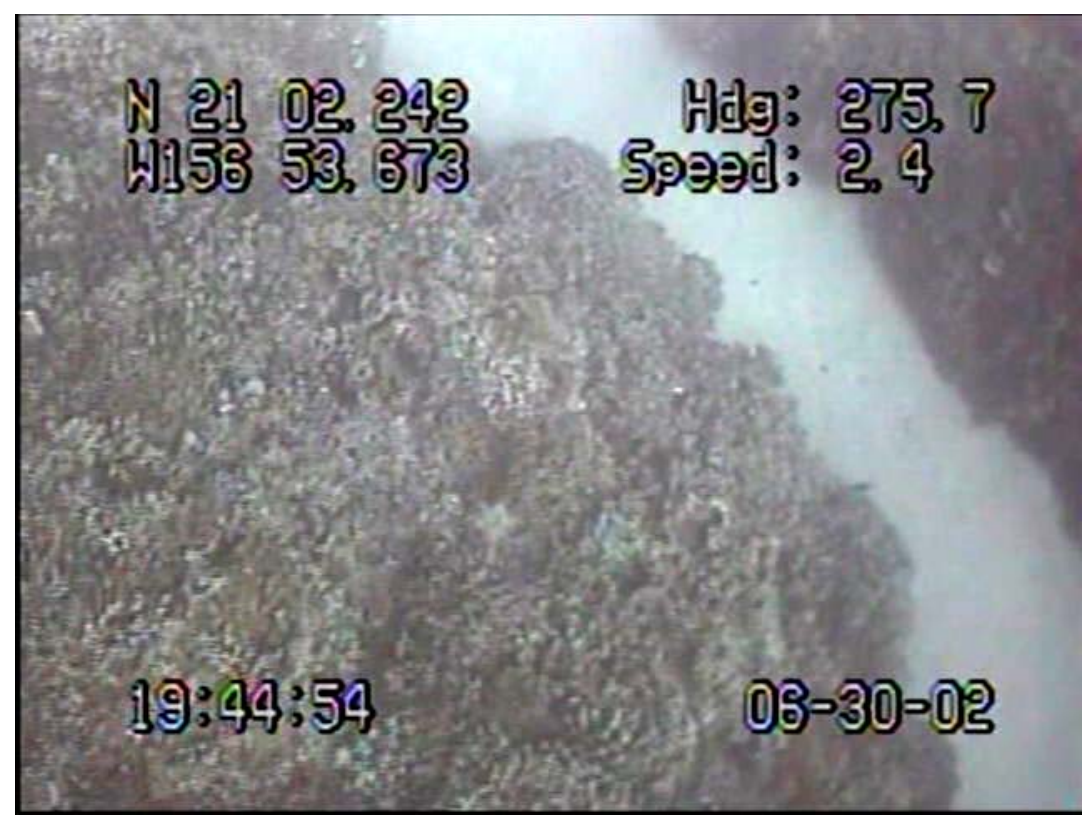


Continuous Macroalgae: Macroalgae covering 90 percent or more of the substrate. May include blowouts of less than 10 percent of the total area that are too small to be mapped independently (less than the MMU). This includes continuous beds of any shoot density (may be a continuous sparse or dense bed). Representative Species: Caulerpa spp., Dictyota spp., Halimeda spp., Lobophora variegata, Laurencia spp.

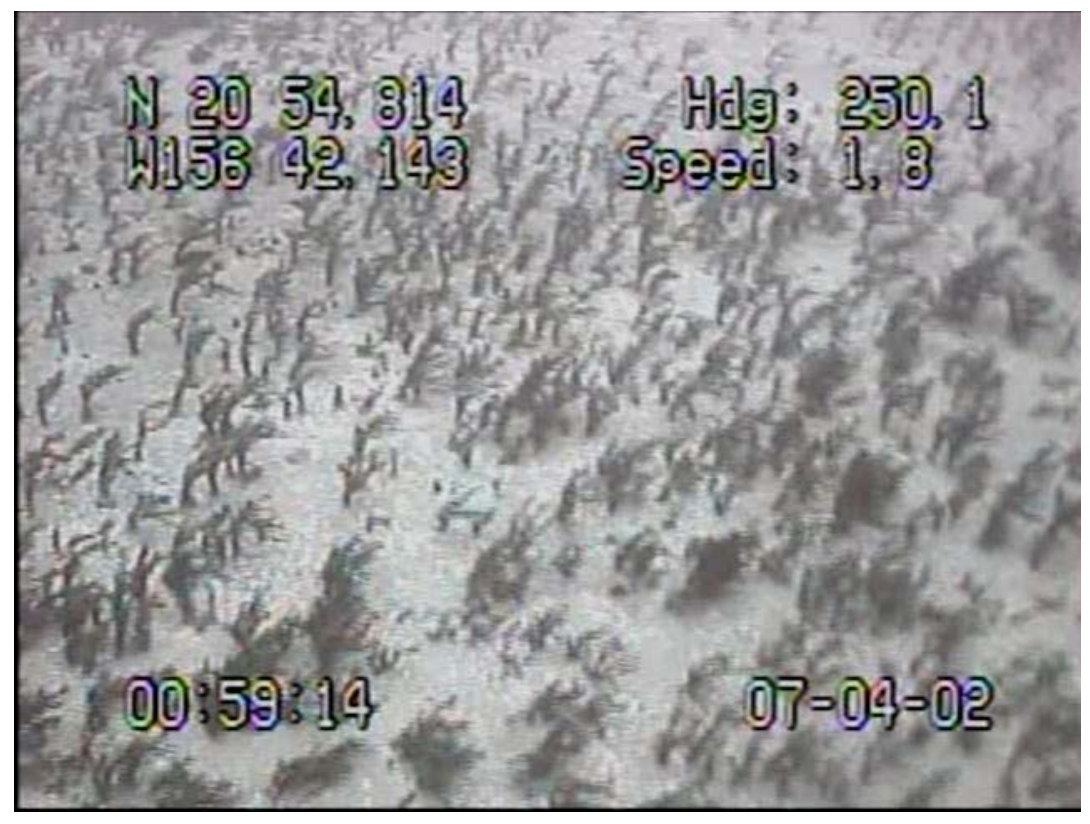

The remainder of this cruise report includes three stand-alone chapters that summarize the surveys and observations for each individual island. Preliminary interpretations of bottom characteristics and transition zones are described. A more comprehensive data set, including water depth, spatial extent of benthic habitats, percent cover, species identification, etc. may be released for each island after more extensive review of the data. Descriptions of the four lines at Maui Nui and the 365 'drops' collected on Molokai are not included in the report. A cruise summary and list of data (tapes) collected can be found in Appendix I and II, respectively. 


\title{
2. Substrate and Benthic Habitat Mapping of the Southern Oahu, Hawaii Insular Shelf
}

\author{
Eric Grossman
}

\section{General Mapping Results}

Twenty kilometers of bottom video data were collected along 17 transects between Kewalo Basin and Koko Head Crater between June 26 and 28, 2002 (Figures 2.1 and 2.2, TABLES 2.1 and 2.2). Fourteen of the 17 transects were oriented perpendicular to the coast, while three were oriented parallel to the coast to tie several cross-shore lines together. Transect locations and orientations were selected to ground truth recent USGS side-scan sonar, seismic reflection, and substrate texture (grain size) surveys and provide large spatial characterization of coral coverage toward NOAA efforts to assess and monitor coral health.

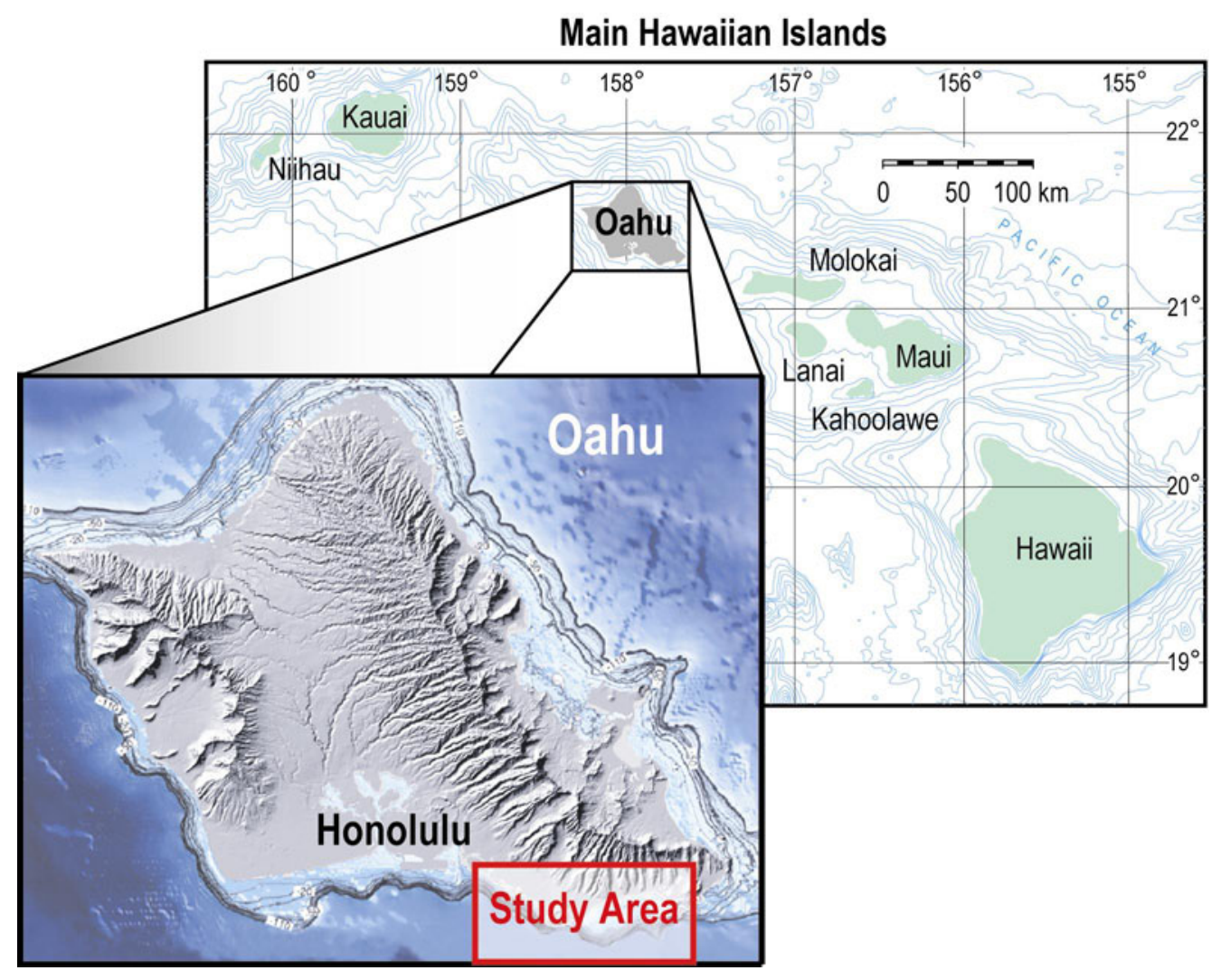

Figure 2.1 Study area for the benthic habitat mapping conducted off the south shore of the Island of Oahu, Hawaii. 


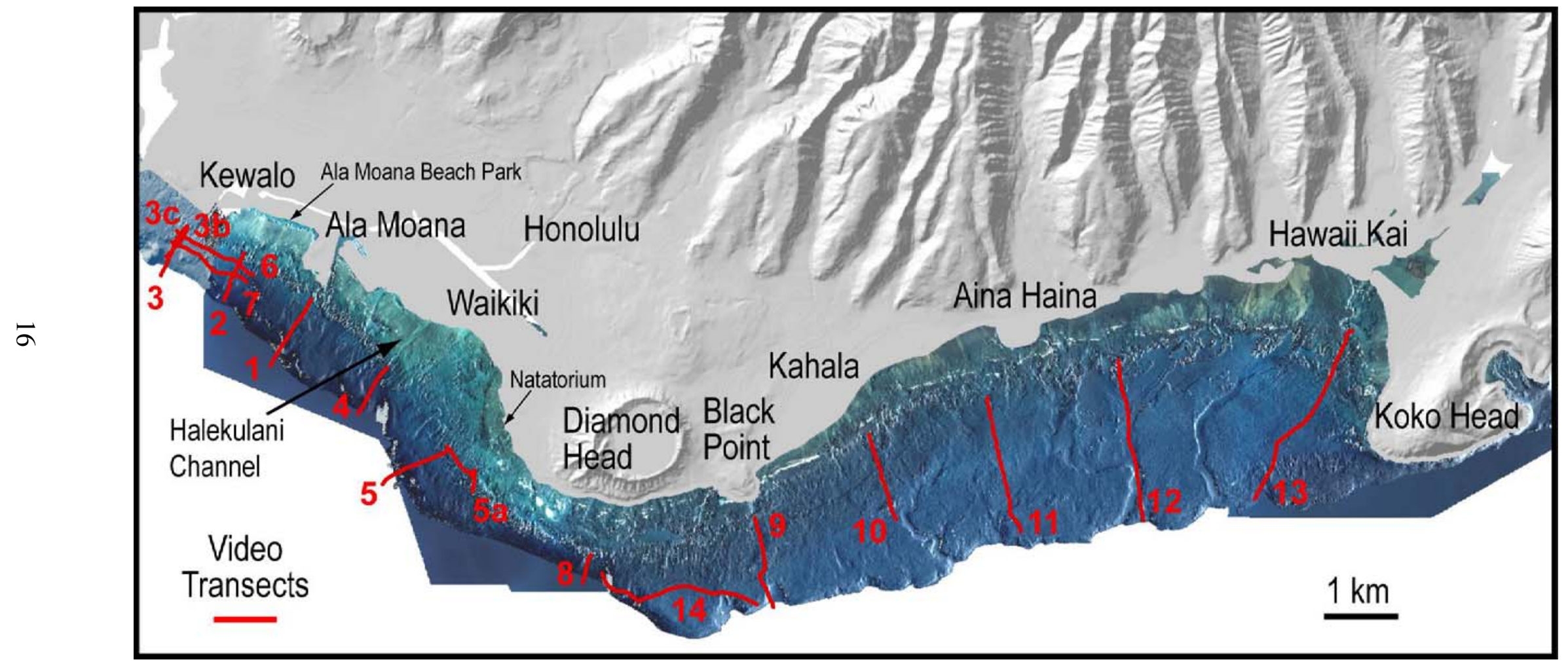

Figure 2.2 Location map of bottom video transects along the South Oahu shelf. 
Results of the bottom characterization of substrate and benthic habitat are presented below for the three general areas, Kewalo to Ala Moana, Diamond Head to Black Point, and Black Point to Koko Head.

\section{Kewalo to Ala Moana}

The Kewalo - Ala Moana region bordering the greatest concentration of urban development on Oahu shows a gradient in coral cover from relatively high cover near Kewalo to very low cover in the center of Waikiki. The topography has high relief near Kewalo and is much flatter and smoother offshore of Ala Moana. The landward portions of Transects 3, 3b, and 3c (water depths of - 4 to $-11 \mathrm{~m}$ ) are characterized by large patch reefs and aggregated coral, where local cover of Porites lobata and Porites compressa ranges between 50\% and 80\%. Patch reefs are separated by active sand channels where sand movement under moderate wave energy scours the base and walls of patch reefs. Along the base and walls, coral cover is low and consists of encrusting coral and coralline algae. The substrate offshore of Kewalo is characterized by steadily decreasing coral cover seaward of the $15 \mathrm{~m}$ contour where fossil reef with thin sand cover dips into a large sand field at approximately $18 \mathrm{~m}$ depth. Coral cover declines rapidly immediately east of the Kewalo Basin channel. Transects 6 and 7 that parallel the Ala Moana Beach Park shoreline show a decrease in coral cover eastward and a general increase in fleshy algae. The substrate along transects 6 and 7 are characterized as uncolonized pavement. Narrow sand channels are common between coral spurs along transect 6 along the west end of Ala Moana Beach Park, while toward the east end, they coalesce into fewer but larger sand fields. Transect 7 is largely composed of uncolonized pavement and sand fields. The reef offshore of Ala Moana (Transect 1), transitions seaward from a sparsely colonized pavement to an uncolonized pavement at the $\sim 10 \mathrm{~m}$ contour. Within the center of Waikiki near the Halekulani Channel (Transect 4) the substrate is low-sloping and largely an uncolonized pavement. Sparse and small head corals occur near the channel, while evidence of sand abrasion is extensive on the higher surfaces of the fossil reef terrace.

\section{Diamond Head to Black Point}

The shelf offshore of Diamond Head and Black Point is narrow and steep. A narrow shallow reef flat that is exposed at low tide fringes the coast between the Natatorium and Diamond Head Beach and is likely fossil. Coralline algae are common on this feature and coral colonies that exist are 
generally sparse and small typically comprised of Porites lobata and Pocillopora meandrina.

Transects 5 and $5 \mathrm{a}$ are characterized by uncolonized pavement that exhibits occasional small $0.5 \mathrm{~m}$ to $1.0 \mathrm{~m}$ scarps running shore-parallel. Sand fields are common near the seaward extent of these two transects and coral cover is sparse. Transects 8 and 14 range between water depths of $15 \mathrm{~m}$ and $25 \mathrm{~m}$ and are dominated by fossil reef pavement and sand fields. Isolated coral communities occur along transect 14, ranging from several meters to $10 \mathrm{~m}$ in diameter, are composed of lobate and encrusting Porites lobata and Montipora capitata and stout branching Pocillopora meandrina and Pocillopora eydouxi corals. Isolated gardens of Halimeda sp. are present in the deeper sand fields in water depths of $15 \mathrm{~m}$ to $20 \mathrm{~m}$. The largely basalt boulder substrate along the landward portion of Transect 9 directly offshore of Black Point is partly colonized by stout-branching Pocillopora meandrina and encrusting Porites lobata corals. Coral cover quickly decreased offshore in water depths $>10 \mathrm{~m}$ where the substrate is primarily uncolonized pavement.

\section{Black Point to Koko Head}

Between Black Point and Koko Head the south coast of Oahu is arcuate with a broad fringing reef that reaches up to $1.5 \mathrm{~km}$ wide between Aina Haina and Hawaii Kai. The reef crest is exposed at low tide and the fore reef drops off steeply in places, especially near Kahala. Coral cover along the majority of the fringing reef is low and composed of small lobate, stout branching and encrusting coral colonies. Offshore of approximately the $10 \mathrm{~m}$ isobath, the fringing reef pinches out onto a wave-abraded pavement composed of volcanic tuff. Several mounds with relief of 2-4 m exist on the flat and low-sloping volcanic terrace and support a healthy community of coral and coralline algae, presumably because they are well removed from sand abrasion below. These mounds are volcanic remnants capped by thin veneers of recent coral and coralline algae growth. Robust, stoutbranching Pocillopora meandrina, Porolithon gardineri, and encrusting Porites lobata corals are common seaward of the reef crest of Kahala (Transect 10). At the base of the fore reef along Transect $10(-12 \mathrm{~m})$, the substrate transitions from partly colonized pavement to uncolonized pavement. A large sand channel emanating from a drowned paleostream crosses the transect between -12 and $-14 \mathrm{~m}$. Seaward of the $14 \mathrm{~m}$ isobath, the Kahala shelf is characterized by uncolonized pavement with sparse volcanic remnants topped by modest coral cover. A similar trend of low coral and coralline algal cover within the reef crest and fore reef that pinches out onto uncolonized pavement and volcanic tuff characterizes Transects 11-13. The only significant difference among these three areas occurs along Transect 13 offshore of Hawaii Kai. Here an 
extensive sand field has formed within the deep embayment immediately west of Koko Head and has filled much of the paleostream channel emanating from Hawaii Kai. Several small reef outcrops occur within the landward portion of the embayment but most of these are uncolonized or only partly colonized by sparse coralline algae and encrusting Porites lobata corals.

TABLE 2.1 Underwater video transect summary for S. Oahu.

\begin{tabular}{lllc}
\hline Line $^{*}$ & Camera & Location & Length $(\mathrm{km})$ \\
\hline OHVM_1 & Sled & E. Ala Moana & 1.05 \\
OHVM_2 & Sled & W. Ala Moana & 0.69 \\
OHVM_3 & Sled & Kewalo & 0.75 \\
OHVM_3b & Seaviewer & Kewalo & 0.3 \\
OHVM_3c & Seaviewer & Kewalo & 0.28 \\
OHVM_4 & Sled & Halekulani Channel & 0.75 \\
OHVM_5 & Sled & Natatorium & 0.98 \\
OHVM_5a & Sled & 50 ft isobath $(15.2 \mathrm{~m}) \mathrm{b} / \mathrm{w}$ lines 5 and 8 & 1 \\
OHVM_6 & Sled & 40 ft isobath $(12.2 \mathrm{~m}) \mathrm{b} / \mathrm{w}$ lines 2 and 3 & 1.23 \\
OHVM_7 & Sled & 60 ft isobath $(18.3 \mathrm{~m}) \mathrm{b} / \mathrm{w}$ lines 2 and 3 & 1.18 \\
OHVM_8 & Sled & Central Diamond Head & 0.43 \\
OHVM_9 & Sled & Black Point & 1.3 \\
OHVM_10 & Seaviewer & Kahala & 1.23 \\
OHVM_11 & Sled & Aina Haina & 1.9 \\
OHVM_12 & Sled & Kawai kui Beach Park & 2.21 \\
OHVM_13 & Sled & Hawaii Kai & 2.7 \\
OHVM_14 & Sled & 50 ft isobath $(15.2 \mathrm{~m}) \mathrm{b} / \mathrm{w}$ Black Pt. and Central Diamond Head & 2.36 \\
\hline
\end{tabular}

*Video data of transect lines OVHM 1-14 are archived on Tapes 1-9 (9). 
TABLE 2.2 UTC, start (SOL) and end (EOL) locations of survey transects.

\begin{tabular}{|c|c|c|c|}
\hline Line & UTC & Latitude $^{*}$ & Longitude* $^{*}$ \\
\hline 1_SOL & 20021781814100 & 21.279578 & -157.847683 \\
\hline 1_EOL & 20021781827540 & 21.271567 & -157.852973 \\
\hline $2 \_\mathrm{SOL}$ & 20021772253480 & 21.285180 & -157.856295 \\
\hline 2_EOL & 20021772308180 & 21.279467 & -157.858887 \\
\hline 3_SOL & 20021772044080 & 21.288418 & -157.863568 \\
\hline 3_EOL & 20021772052420 & 21.282517 & -157.866968 \\
\hline 3b_SOL & 20021772158380 & 21.288210 & -157.863510 \\
\hline 3b_EOL & 20021772202220 & 21.286008 & -157.864822 \\
\hline 3c_SOL & 20021772235020 & 21.286585 & -157.864533 \\
\hline 3c_EOL & 20021772252120 & 21.284793 & -157.866277 \\
\hline 4_SOL & 20021782052000 & 21.271253 & -157.837937 \\
\hline 4_EOL & 20021782101040 & 21.265725 & -157.841787 \\
\hline 5_SOL & 20021782014220 & 21.261127 & -157.830477 \\
\hline 5_EOL & 20021782028040 & 21.257228 & -157.838655 \\
\hline 5a_SOL & 20021781949260 & 21.256243 & -157.827082 \\
\hline 5a_EOL & 20021782006100 & 21.261702 & -157.830348 \\
\hline 6_SOL & 20021772320120 & 21.287905 & -157.864905 \\
\hline 6_EOL & 20021772336000 & 21.282490 & -157.855035 \\
\hline 7_SOL & 20021772343360 & 21.281642 & -157.855987 \\
\hline 7_EOL & 20021772357140 & 21.286523 & -157.865530 \\
\hline 8_SOL & 20021792154580 & 21.248512 & -157.811957 \\
\hline 8_EOL & 20021792201060 & 21.245163 & -157.813057 \\
\hline 9_SOL & 20021792234460 & 21.252843 & -157.790883 \\
\hline 9_EOL & 20021792253280 & 21.242093 & -157.788567 \\
\hline 10_SOL & 20021790452400 & 21.262762 & -157.776022 \\
\hline 10_EOL & 20021790508420 & 21.252520 & -157.772693 \\
\hline 11_SOL & 20021790408360 & 21.250938 & -157.756743 \\
\hline 11_EOL & 20021790436400 & 21.267033 & -157.760760 \\
\hline 12_SOL & 20021790314260 & 21.271420 & -157.743948 \\
\hline 12_EOL & 20021790349380 & 21.252193 & -157.740847 \\
\hline 13_SOL & 20021790214240 & 21.274853 & -157.713845 \\
\hline 13_EOL & 20021790254120 & 21.254625 & -157.726578 \\
\hline 14_SOL & 20021792259080 & 21.242437 & -157.790627 \\
\hline 14_EOL & 20021792336020 & 21.246328 & -157.810595 \\
\hline
\end{tabular}

UTC time format is YYYYDDDHHMMSST (year, Julian_day, hour, minute, seconds, tenths) Coordinates are decimal degrees, WGS84 


\section{Substrate and Benthic Habitat Mapping of the Southern Molokai, Hawaii Insular Shelf}

Bruce M. Richmond

Fifteen transects (Figure 3.1, Tables 3.1 and 3.2) were collected off the southern coast of Molokai between June 30 and July 2, 2002. Both the SLED and SEAVIEWER camera systems were used to characterize the seabed in support of coral community studies (e.g. Jokiel et al., 2004), reef history and development (e.g. Engels et al., 2004), reef morphology (e.g. Storlazzi et al., 2003), and benthic habitat mapping (e.g. Brown et al., 2004). Both reef-parallel and reef-normal video transects were collected and extended from where it was navigably safe in the shallow areas ( 4-6 $\mathrm{m}$ water depths) offshore to beyond the depth where significant coral colonies occurred, generally 25-30 m.

The south coast of Molokai encompasses the best developed fringing reef of the main 8 Hawaiian Islands. An extensive reef flat, up to $1,500 \mathrm{~m}$ wide, is fronted by a reef crest and well-developed fore reef zones. The fringing reef extends for about $50 \mathrm{~km}$ along the semi-protected southern coast. Variations in reef morphology and habitat composition appear to be controlled by a combination of oceanographic influences (primarily wave energy), terrigenous input, and antecedant reef structure (Storlazzi et al., 2003; 2005; Barnhardt et al., 2003).

\section{Individual Transect Descriptions}

The following are brief descriptions of the general orientation, coverage, and bottom type observed for each video transect collected along southern Molokai. Table 3.1 summarizes the camera system used, general location, and line length for each transect. The line numbering follows the original field designation.

MVM1 is a reef normal transect. The line traverses a deep "blue hole" (no visible bottom on the video) and extends over the reef crest and through the fore reef, to water depths greater than $35 \mathrm{~m}$. The reef section consists mostly of aggregated coral with scattered sand pockets and channels, locally comprising up to $50 \%$ of the overall bottom type. The deeper fore reef portion of the line is composed of sand, colonized by up to $50 \%$ macroalgae (Halimeda sp.?) with localized coverage approaching $100 \%$. 


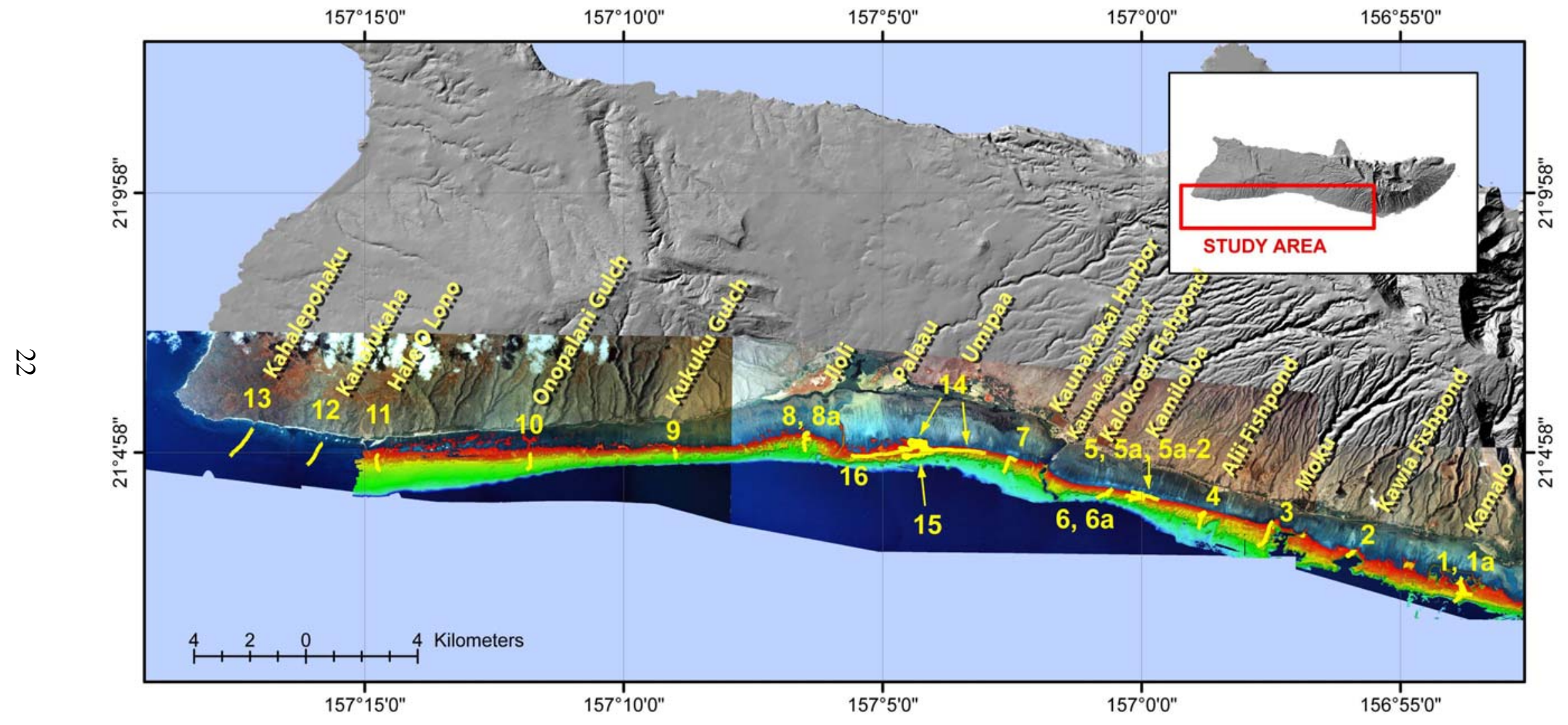

Figure 3.1. Underwater video trackline locations overlain on a composite image (color vertical aerial photography, SHOALS lidar, and DEM shaded-relief) of the Molokai study area. 
MVM1a is an east to west, reef parallel transect along the $\sim 10 \mathrm{~m}$ depth contour. Aggregated coral is the dominant bottom type for most of the line with scattered sand pockets and a few small sand channels (grooves).

MVM2 begins as a reef parallel line running east to west near the reef crest (and back reef areas) then veers obliquely offshore towards the southwest and the deeper fore reef. A loop is made at the fore reef and the track heads towards the northeast and reef crest where a final turn to the west is made. The transect is comprised primarily of 3 bottom types: shallow sand of the back reef area; aggregated coral on the reef crest and reef front, and sand and macroalgae of the deeper fore reef. Video quality is poor over the fore reef area and generally good over the reef front and in shallower areas.

MVM3 begins as a north to south, reef-normal transect that gradually bends to the west because of the wind-induced westerly directed currents pushing the vessel to the west. The line starts in very rugged aggregated coral terrain with spur-and-groove morphology with abundant encrusting coral morphotypes. Bottom relief is $2-4 \mathrm{~m}$ in average water depths of $\sim 5 \mathrm{~m}$. The channels (grooves) have limited sand and rubble deposits. In general, overall rugosity becomes lower and the number of branching corals increases downslope. A large sediment-rich depression is encountered between 10 and $15 \mathrm{~m}$ water depths. Video quality is generally good over the entire line.

MVM4 is predominantly a southwest directed reef-normal transect, however, there is a loop over shallow $(5-15 \mathrm{~m})$ reef near the start of the line. During the loop the bottom is a mixture of mostly sand with macroalgae (10-30\%) and patches of aggregated coral. After the loop the line begins a reef normal transect to the southwest. Shallow areas $(<10 \mathrm{~m})$ are mostly sand with macroalgae (10-40\%) interspersed with areas of pavement and encrusting coral and macroalgae. Video image quality is not good in this shallow area but improves in deeper water (20-30 m). At about $20 \mathrm{~m}$ water depth aggregated coral becomes predominant with $80-100 \%$ coral coverage, mostly branching and platy types, and isolated sand pockets. Visibility decreases again at $\sim 30 \mathrm{~m}$ where there is a combination of aggregated coral and sand with macroalgae. 
MVM5 is a west-northwest oriented, reef parallel line, near the reef crest, in less than $5 \mathrm{~m}$ of water. The seafloor alternates between colonized pavement and rippled sand sheets with scattered rubble layers and encrusting coralline algae.

MVM5a is an oblique, reef-normal line directed to the southwest. The transect starts in very shallow water $(<5 \mathrm{~m})$ near the reef crest and extends to about $25 \mathrm{~m}$ water depth. Colonized pavement with scattered rippled sand bodies comprise the $<10 \mathrm{~m}$ shallow segment, with a gradual transition to aggregated coral (although some colonized pavement is still present). At $\sim 20 \mathrm{~m}$ water depth, sediment with macroalgae (Halimeda sp.+?) becomes the dominant bottom type. Sediment, where present, appears to be poorly sorted with some granule/coarse sand particles.

MVM6 is a south-southwest, reef-normal transect starting in about $5 \mathrm{~m}$ of water and ending in approximately $30 \mathrm{~m}$ of water. The shallow water section begins on a pavement surface with encrusting coralline algae and isolated small corals. At $\sim 10 \mathrm{~m}$ the seafloor descends into a sand rich reef front terrace with 10-30\% macroalgae cover (line ends at $\sim 30 \mathrm{~m}$ water depth).

MVM6a is an oblique, reef-normal line oriented towards the southwest. The line starts near the reef crest in $<5 \mathrm{~m}$ water depth. Colonized pavement is prominent to $\sim 10 \mathrm{~m}$ depth and includes isolated compact corals, scattered macroalgae, and patchy veneers of sand and/or rubble. From $\sim 10$ $\mathrm{m}$ to $20 \mathrm{~m}$ depths the seafloor is mostly sand, often rippled, with 10-30\% macroalgae coverage, pavement, and/or algal mat patches (80-100\% coverage). There is a broad transition zone from the sandy seafloor to aggregated coral $(\sim 25 \mathrm{~m})$ that occurs as the line traverses a sediment-filled channel to a coral-covered ridge. Scattered pockets of macroalgae-covered sand occur within the aggregated coral zone. A transition to a dominantly sand bottom with 20-50\% macroalgae cover occurs at $\sim 30 \mathrm{~m}$ depth.

MVM7 is a reef-parallel line oriented towards the west, just seaward of the reef crest in shallow water $(5-10 \mathrm{~m})$. The seafloor is composed of a spur-and-groove zone with mostly aggregated coral ridges separated by narrow channels (grooves). The vertical relief of the seabed is on the order of 1-2 $\mathrm{m}$ and branching and encrusting corals comprise $80-100 \%$ of the bottom. 
MVM7a is a reef-normal line, starting at about $5 \mathrm{~m}$ water depth. Along this line the seafloor alternates between aggregated coral and rippled sand channels. The aggregated coral covers $80-$ $100 \%$ of the hardground surface. There are occasional broad expanses of rippled sand (several to $5+\mathrm{m}$ wide). Aggregated coral continues on the fore reef to $\sim 25 \mathrm{~m}$ depth. A sand terrace and/or channel, with patches of aggregated coral, occurs beyond the reef front. At around $30 \mathrm{~m}$ depth it is difficult to discern if the bottom is aggregated coral, colonized pavement, or sand covered with macroalgae because of poor video quality.

MVM8 is a reef-normal line with a loop near the start of line. The shallow portion $(<10 \mathrm{~m}$ depth) consists mostly of aggregated coral with $90-100 \%$ coverage of the seafloor. The aggregated coral is interrupted by isolated channels filled with sand and rubble. Over the very shallow portions of the line the seafloor consists of aggregated coral and scattered patches of reef rubble. The fore reef is bordered by a sand terrace ( $20 \mathrm{~m}$ depth) with occasional blocks of aggregated coral. Bottom variations along the terrace include: sand with rubble, sand with macroalgae (10-30\%), and smooth sand with bioturbation structures (mounds). The line crosses over a deeper patch reef covered with rubble and aggregated coral, beyond which the seafloor is predominantly sand with prolific Halimeda sp. (40-80\% coverage).

MVM8a is a west to east reef-parallel line that approximately follows the $-5 \mathrm{~m}$ contour. The seafloor is mostly aggregated coral interrupted by some rubble veneers and isolated sand pockets and small sand channels. The bottom relief is on the order of 1-2 $\mathrm{m}$. Compact branching corals and crevices are common.

MVM9 is a reef-normal line extending from about 5 to $26 \mathrm{~m}$ water depth. The shallow section is characterized by aggregated coral with isolated sand channels. The fore reef sand terrace includes: rippled sand (somewhat degraded ripples); undifferentiated macroalgae 10-40\%; and Halimeda sp. meadows with $20-50 \%$ bottom coverage. In general, ripple size and spacing decreases with increasing depth.

MVM10 is a reef-normal line oriented toward the south. The line begins in about $7 \mathrm{~m}$ of water and ends in around $25 \mathrm{~m}$ of water. The reef crest and shallow fore reef consist mostly of aggregated coral broken by occasional sand channels filled with rippled sediment. Relief of the coral surface 
is on the order of $\sim 1-2 \mathrm{~m}$ and consists predominantly of compact branching and encrusting corals. The transect follows the edge of a larger channel which is floored mostly by rippled sand. The larger channel begins at $\sim 10 \mathrm{~m}$ depth where the track line follows the channel flanked by a ridge of aggregated coral. Within the channel itself there are aggregated coral ridges and pinnacles which are surrounded by areas of rippled sand ( $15 \mathrm{~m}$ depth). Most of the channel floor consists of clean rippled sand that merges into the sand terrace fronting the reef. The sand terrace has abundant macroalgae (Halimeda sp. 10-30\%).

MVM11 is a reef-normal line beginning at about $5 \mathrm{~m}$ water depth where the seafloor is dominated by aggregated coral (1-2 m relief) and occasional sand channels as part of incipient spur-andgroove development zone. In about $10 \mathrm{~m}$ of water there is a large sand flat embedded within the reef complex. The sand flat is part of a reef-parallel arrangement of alternating coral ridges and low-lying sand flats. Further seaward the sand flat is replaced by a coral covered ridge dominated by compact branching and encrusting corals and occasional sand channels. There is a gradual transition from the coral-dominated reef front to the sediment-dominated reef front terrace. The base of reef front contains rubble and patches of aggregated coral and colonized pavement. The terrace is characterized by low-relief rippled sand and patches of macroalgae (mostly Halimeda $s p$.). The transect ends in rippled sand at $\sim 22 \mathrm{~m}$ depth.

MVM12 is a reef-normal line in an area of alternating reef ridges and intervening sand flats. The line starts in shallow water where the seafloor is a combination of aggregated coral and colonized pavement with a predominance of coral heads. Occasional shallow sand channels are present. The hard bottom abruptly changes to a reef-parallel sand flat with mostly large-scale ripples that are long-crested and reef-parallel which grade into degraded bioturbated ripples. The sand flat abruptly gives way to an east-west oriented linear reef of aggregated coral mixed with coral colonized pavement. Coral coverage varies from 70-100\% and consists of low branching and encrusting corals. Further seaward is another reef-parallel, elongated sand flat covered with rippled sand. The ripples grade from long-crested large ripples at the landward edge of the flat to smaller ripples, and finally to a macroalgae (10-40\%) covered sand flat. A third hard bottom is encountered and consists of colonized pavement with scattered corals, isolated sand veneers, rubble pockets, and patches of macroalgae. Some areas have dense coral coverage $(>80 \%)$ and there are also occasional linear sand bodies. Towards end of line the seafloor appears to be more aggregated 
coral than colonized pavement. The end of the line is marked by a reef parallel sand body of longcrested degraded ripples with debris-filled troughs.

MVM13, the westernmost reef-normal line, begins in shallow water where the seafloor consists of uncolonized pavement of spur-and-groove morphology. Approximately 60-70\% of the seafloor is colonized pavement while $30-40 \%$ consists of small sand channels. The sand areas are characterized by long-crested shore-parallel ripples and occasional rubble deposits. The colonized pavement areas contain scattered coral heads and rubble on pavement surface with occasional sand ribbons. Encrusting coralline algae and macroalgae are also present. Sand areas increase down slope with a concomitant increase in macroalgae coverage (Halimeda sp. mostly). Interspersed with the sand flats are colonized pavement. The pavement is generally sparsely colonized with scattered corals, macroalgae, and coralline algae. Scattered sand pockets and ribbons (veneers) are also present. Further seaward the hard bottom is replaced by a low relief, reef-parallel sand body with 10-30\% macroalgae coverage (mostly Halimeda sp.). Within the sand body there are scattered coral heads.

MVM5a-2 is a long reef-parallel transect running east to west and roughly following the $10 \mathrm{~m}$ contour. The line begins east of Kaunakakai Wharf and heads towards the west. The seafloor alternates between three primary bottom types: aggregated coral, colonized pavement, and sand.

MVM14 is a shallow ( 5-7 m), reef-parallel line from east to west beginning west of Kaunakakai Wharf. The line includes a loop through a reef-enclosed blue hole. Except for the blue hole, which is sediment filled, the line is dominated by aggregated coral with typically $80-100 \%$ coral coverage with substantial thickets of branching corals. The aggregated coral is broken by occasional sand channels filled with clean, rippled sand. The blue hole is sand-floored with ripples that appear to be active in places and degraded in others.

MVM15 is a west to east reef-parallel line in 5-15 m water depth (the line contains several loops). Throughout the transect the seafloor is mostly aggregated coral with numerous small, and several large, sand channels. The aggregated coral is predominantly branching corals with $80-100 \%$ coverage. Sand areas are typically clean rippled sand. 


\section{Southern Molokai Video Survey Summary}

The fringing reef of southern Molokai is the best-developed reef in the main Hawaiian Islands. It extends for about $50 \mathrm{~km}$ along the coast with reef flat widths greater than $1500 \mathrm{~m}$ in the central reef area. The reef is narrower and less well developed on the eastern and western margins where wave and current activity is higher. The reef flat is generally shallow, well defined, and covered with a veneer of mixed carbonate-terrigenous sediment and patches of macroalgae (Calhoun and Field, 2000). Incorporated into the fringing reef are numerous blue holes. These are deep, steep-sided depressions that are characterized by aggregated corals around the rim and sediment filled interiors. Isolated coral heads, colonized pavement, and reef rubble occur landward of the reef crest.

The reef crest is usually defined by a zone of breaking waves and is marked by high cover of encrusting coralline algae over pavement, patches of rubble, and coral. Active reef accretion extends from near the reef crest down to about $27 \mathrm{~m}$ water depth (Logan et al., in press).

Areas of prolific coral growth are marked by a highly rugose seafloor with up to $2 \mathrm{~m}$ of vertical relief. Spur-and-grooves are well developed along much of the fore reef zone and vary morphologically (size and spacing) with wave exposure (Storlazzi et al., 2003). The spurs (ridges) are primarily composed of aggregated coral while the intervening grooves (channels) are typically smooth, U-shaped, and partially filled with sand and/or coral rubble. Areas of aggregated coral are often interspersed with scattered sand pockets. Coral species distribution and coverage is related to wave energy with more species, but lower coverage, in the higher energy zones at the east and west margins (Storlazzi et. al., 2005). Fore reef areas often abruptly merge into a reef front terrace that is predominantly covered by sediment derived from either the adjacent reef, the land, or in-situ production. Macroalgae cover is typically high along the fore reef sand bodies. 
TABLE 3.1. Underwater video transect summary for southern Molokai.

\begin{tabular}{llll}
\hline Line* & Camera & Location & Length $(\mathrm{km})$ \\
\hline MVM_1 & Sled & Kamalo W & 0.97 \\
MVM_1a & Seaviewer & Kamalo W & 0.55 \\
MVM_2 & Seaviewer & Kawia Fishpond & 0.79 \\
MVM_3 & Seaviewer & Moku & 1.09 \\
MVM_4 & Seaviewer & Alii Fishpond & 1.18 \\
MVM_5 & Seaviewer & Kamiloloa & 0.99 \\
MVM_5a & Seaviewer & Kamiloloa & 0.55 \\
MVM_5a-2 & Sled & Kamiloloa & 0.66 \\
MVM_6 & Seaviewer & Kalokoeli Fishpond & 0.30 \\
MVM_6a & Seaviewer & Kalokoeli Fishpond & 0.64 \\
MVM_7 & Seaviewer & Kaunakakai Harbor W & 0.83 \\
MVM_7a & Seaviewer & Kaunakakai Harbor W & $? ?$ \\
MVM_8 & Seaviewer & Iloli & 1.09 \\
MVM_8a & Seaviewer & Iloli & 0.20 \\
MVM_9 & Seaviewer & Kukuku Gulch & 0.33 \\
MVM_10 & Seaviewer & Onopalani Gulch & 0.63 \\
MVM_11 & Seaviewer & Hale O Lono & 0.63 \\
MVM_12 & Seaviewer & Kanalukaha & 0.90 \\
MVM_13 & Seaviewer & Kahalepohaku & 1.23 \\
MVM_14 & Sled & Umipaa & 4.51 \\
MVM_15 & Sled & Palaau & 3.37 \\
\hline & & Total length surveyed (km) & 21.44 \\
\hline
\end{tabular}

*Video data of transect lines MVM 1-15 are archived on tapes 10-16 (7). 
TABLE 3.2 UTC, start (SOL) and end (EOL) locations of survey transects.

\begin{tabular}{|c|c|c|c|}
\hline Line & UTC & Latitude & Longitude \\
\hline 1_SOL & 20021811838400 & 21.042805 & -156.897072 \\
\hline 1_EOL & 20021811853100 & 21.035090 & -156.899580 \\
\hline 1a_SOL & 20021811943400 & 21.037237 & -156.893670 \\
\hline 1a_EOL & 20021811951100 & 21.037975 & -156.898763 \\
\hline 2_SOL & 20021812027100 & 21.051045 & -156.931343 \\
\hline 2_EOL & 20021812037500 & 21.050120 & -156.933185 \\
\hline 3_SOL & 20021812056200 & 21.060695 & -156.957888 \\
\hline 3_EOL & 20021812111500 & 21.052940 & -156.962840 \\
\hline 4_SOL & 20021812129000 & 21.063760 & -156.979432 \\
\hline 4_EOL & 20021812145200 & 21.058658 & -156.981830 \\
\hline 5_SOL & 20021812156000 & 21.067738 & -156.994662 \\
\hline 5_EOL & 20021812207100 & 21.070290 & -157.003517 \\
\hline 5a_SOL & 20021812214200 & 21.069707 & -156.999440 \\
\hline 5a_EOL & 20021812221500 & 21.067622 & -157.004083 \\
\hline 6_SOL & 20021821754500 & 21.071148 & -157.009595 \\
\hline 6_EOL & 20021821758100 & 21.068983 & -157.011305 \\
\hline 6a_SOL & 20021821802500 & 21.071175 & -157.009558 \\
\hline 6a_EOL & 20021821811300 & 21.068333 & -157.014628 \\
\hline 7_SOL & 20021821828300 & 21.080318 & -157.040480 \\
\hline 7_EOL & 20021821832200 & 21.076528 & -157.044473 \\
\hline 7a_SOL & 20021821832300 & 21.081230 & -157.042710 \\
\hline 7a_EOL & 20021821841200 & 21.076407 & -157.044477 \\
\hline 8_SOL & 20021821911000 & 21.087403 & -157.108350 \\
\hline 8_EOL & 20021821927500 & 21.083405 & -157.108473 \\
\hline 8a_SOL & 20021821934400 & 21.088543 & -157.109517 \\
\hline 8a_EOL & 20021821943400 & 21.087260 & -157.108616 \\
\hline 9_SOL & 20021822002600 & 21.083910 & -157.150292 \\
\hline 9_EOL & 20021822008100 & 21.081102 & -157.149850 \\
\hline 10_SOL & 20021822033300 & 21.082573 & -157.197007 \\
\hline 10_EOL & 20021822041200 & 21.077515 & -157.197850 \\
\hline 11_SOL & 20021822102300 & 21.082167 & -157.246170 \\
\hline 11_EOL & 20021822111200 & 21.077128 & -157.245580 \\
\hline 12_SOL & 20021822122500 & 21.085837 & -157.264243 \\
\hline 12_EOL & 20021822133600 & 21.079105 & -157.268487 \\
\hline 13_SOL & 20021822146600 & 21.090390 & -157.285995 \\
\hline 13_EOL & 20021822201000 & 21.081723 & -157.293005 \\
\hline 5a-2_SOL & 20021831847300 & 21.067922 & -156.999192 \\
\hline 5a-2_EOL & 20021831858200 & 21.069192 & -157.005237 \\
\hline 14_SOL & 20021831956100 & 21.082718 & -157.050270 \\
\hline 14_EOL & 20021832052400 & 21.084012 & -157.077922 \\
\hline 15_SOL & 20021832055500 & 21.082567 & -157.076882 \\
\hline 15_EOL & 20021832150000 & 21.084377 & -157.071267 \\
\hline
\end{tabular}

UTC time format is YYYYDDDHHMMSST (year, Julian_day, hour, minute, seconds, tenths) Coordinates are decimal degrees, WGS84 


\title{
4. Substrate and Benthic Habitat Mapping of the Western Maui, Hawaii Insular Shelf
}

\author{
Ann E. Gibbs
}

Over 32 kilometers of underwater video was collected along 30 transects between Kahana and the Ahihi-Kinau Natural Area Preserve between July 3 and 6, 2002 (Figure 4.1, Tables 4.1 and 4.2). The field excursion was reconnaissance in nature, with the objectives of characterizing overall bottom type and identifying regional transitions in reef morphology, coral cover, and coral health. Seven fundamentally distinct regions, based on bottom type and reef morphology, were delineated along the west coast of Maui (Figure 4.1). From north to south they are: Kahana, Honokowai, Kaanapali, Lahaina, Olowalu, Kihei, Wailea, and the Ahihi-Kinau Preserve. Preliminary observations, interpretations, and maps of the seven regions are presented below.

Prior to this fieldwork, published references to the location of coral reefs on the island of Maui were limited to NOS (National Ocean Service) navigation charts, the REEFBASE web site (http://www.reefbase.org), Coral Reefs of the World (Wells and Jenkins, 1988), recreational dive books, miscellaneous gray literature, communication with knowledgeable locals, and personal experience. At the time of this survey, the NOAA benthic habitat classification map for the island of Maui was complete, but not publicly available. The maps are now available online from the NOAA Biogeography Program at: http://biogeo.nos.noaa.gov/products/hawaii cd/. The NOAA benthic habitat mapping was based primarily on the interpretation of the 2000 aerial photography collected from Poelua Bay on Maui's north shore, west and south to Keawa Bay on the south/southeast shore of Maui, near the town of Hana. A gap in coverage exists between Mahinahina Point and Hanakaoo Point. Figure 4.2 shows the distribution of coral reef and colonized hardbottom as mapped on the original NOS charts and the recently published NOAA benthic habitat maps. 


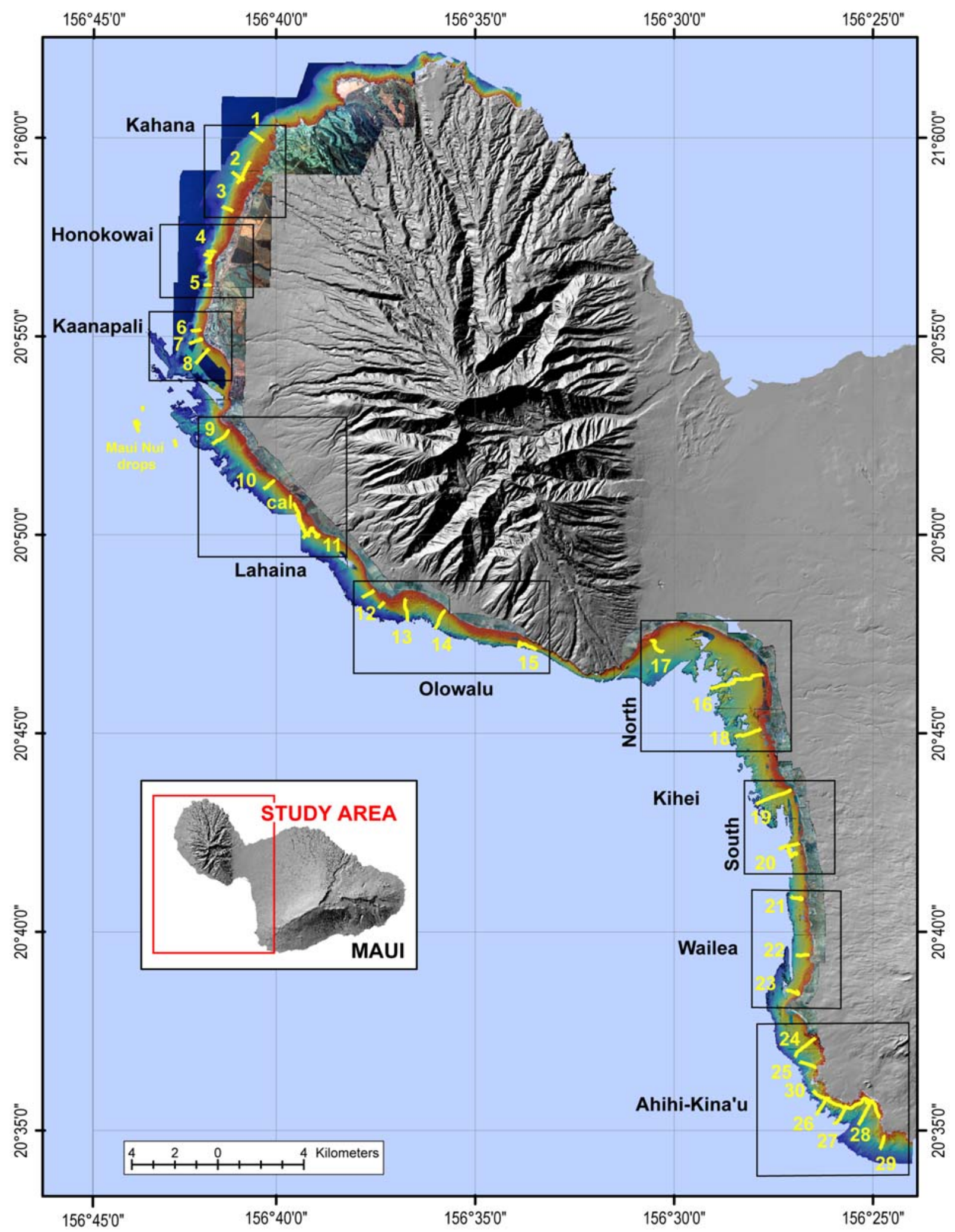

Figure 4.1. Underwater video trackline locations overlain on a composite image (color vertical aerial photography, SHOALS lidar, and DEM shaded-relief) of the Maui study area. 


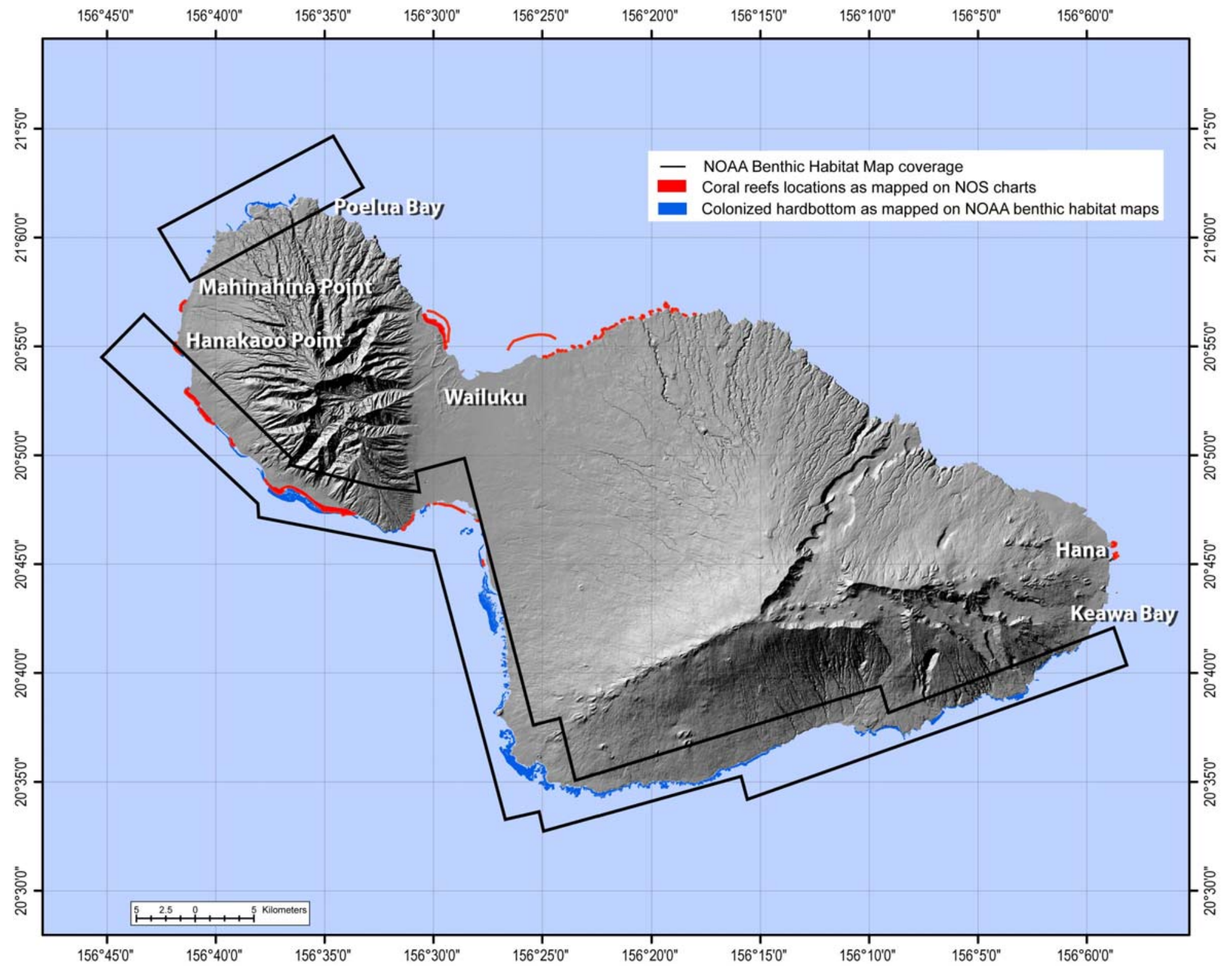

Figure 4.2. Location of coral reefs and colonized hardbottom on the island of Maui as mapped on NOS charts (red) and NOAA benthic habitat maps (blue). 


\section{General Mapping Results}

\section{Kahana}

One shore parallel and three shore normal transects were collected in the Kahana region, between Napili Bay and Kapua (Figure 4.3). The Kahana region is characterized by uncolonized sand fields and uncolonized pavement. Some Halimeda sp., turf algae, and few encrusting corals were observed offshore. Lines VVM2 and VVM2a were collected over the location of the USGS instrument tripod (Storlazzi and Jaffe, 2003).

\section{Honokowai}

One shore parallel and four shore normal transects were collected in the Honokowai region (Figure 4.4). This area is characterized by an extensive, colonized reef platform and associated spur-andgroove structure. It is the most northern continuous reef complex on West Maui. North of this area, coral assemblages are typically confined to areas close to shore, within the rocky embayments.

The Honokowai transects (VVM4) show high coral cover inshore ( 8 m water depth) transitioning to sand with fairly dense beds of Halimeda sp. in deeper water. The reef appeared to be relatively healthy. At the Kahikili CRAMP site (VVM5), our line started in a water depth deeper than the deepest CRAMP site. The transect showed high coral coverage and transitions similar to those at VVM4.

\section{Kaanapali}

A cluster of three transects were collected around Hanakaoo Point in Kaanapali in order to evaluate potential transitions in reef morphology around a headland (Figure 4.5). Beach profile data collected in the area show large seasonal variations in beach volume at this location, reflecting the strong seasonal changes in wave energy and direction along this coast (Gibbs et al., 2002; Eversole and Fletcher, 2003). 
Off the north side of Hanakaoo Point (VVM6), good coral cover was observed close to shore, while sparse coral cover in water deeper than $10 \mathrm{~m}$ transitioned rapidly to sand colonized with thick beds of Halimeda sp. offshore.

Off the middle of Hanakaoo Point (VVM7), high cover, healthy coral close to shore transitioned quickly to somewhat degraded, sparsely colonized pavement and an uncolonized sand field about $600 \mathrm{~m}$ offshore. This transect, where the first occurrence of significant pavement was observed, showed very different bottom character than anything observed to north. This may also reflect, or have implications for determining differences in sediment transport pathways and sand availability to beaches. For example, do the large seasonal changes in wave energy drive north-south/southnorth transport of offshore sediment, similar to what is observed on the adjacent beaches? (See Gibbs et al., 2002, and Eversole and Fletcher, 2003).

Line VVM8, off the south side of Hanakaoo Point, was located in a broad reentrant in the carbonate platform, perhaps indicating a site of an old stream channel and potential fresh water influx. Severe beach erosion is also apparent at this location in 1997 aerial photography. Nearshore coral cover appeared more degraded and fundamentally different than coral to the north. Offshore, colonized pavement alternated with algae (Halimeda sp.?) covered sand flats.

An interesting note, the offshore bathymetry in this area, continuing south of Lahaina, is quite unusual and may represent a fossil reef and/or some type of ravinement surface. Unfortunately, there are many gaps in the SHOALS data in this area. This should be an interesting and important area for future work because of both the transitions in benthic environments, as well as possible anthropogenic pressures of coastal development in the region. 


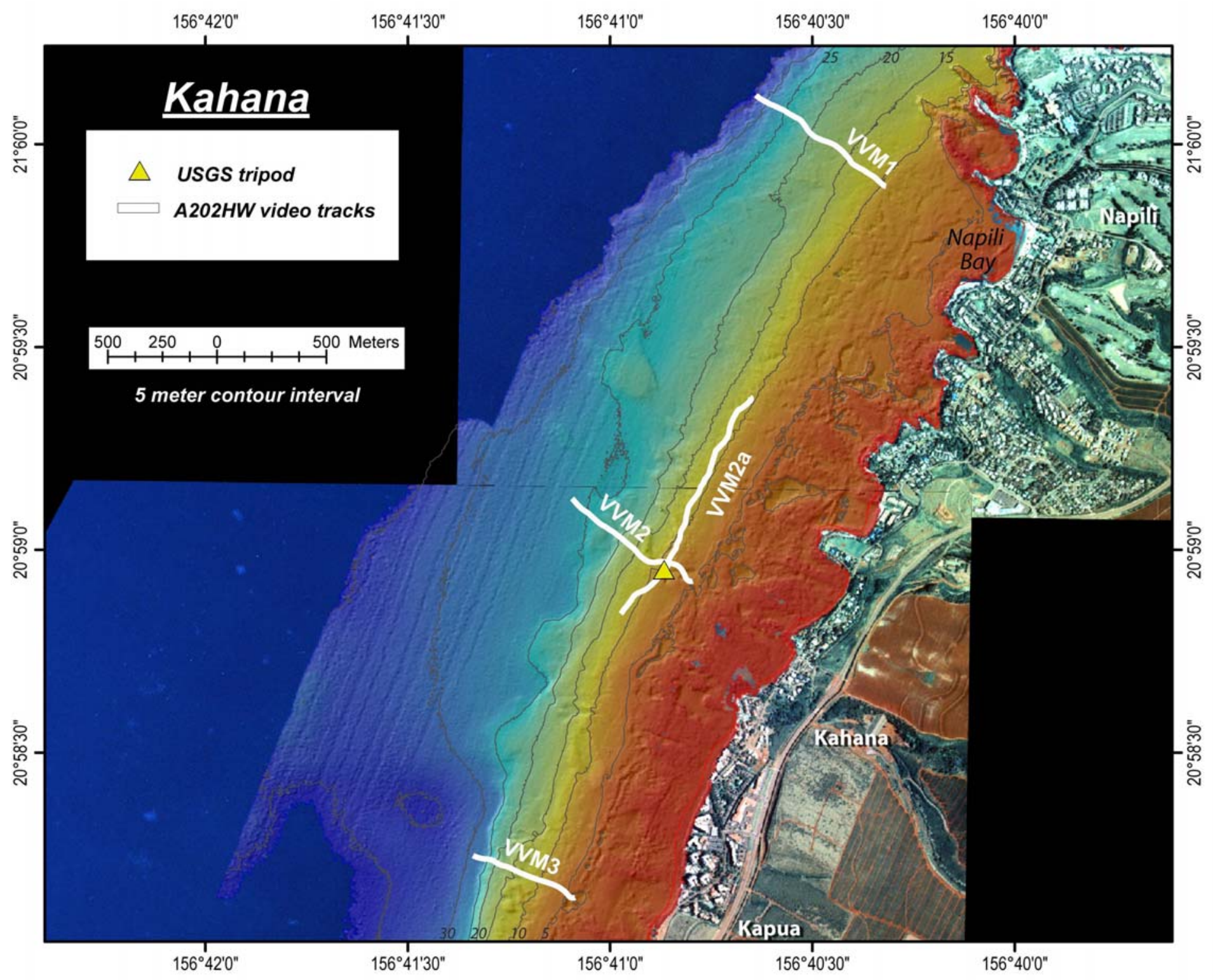

Figure 4.3 Underwater video trackline locations and the location of the USGS instrument tripod overlain on a composite image (color vertical aerial photographv and SHOALS lidar bathymetrv) within the Kahana reqion off the west coast of Maui. 


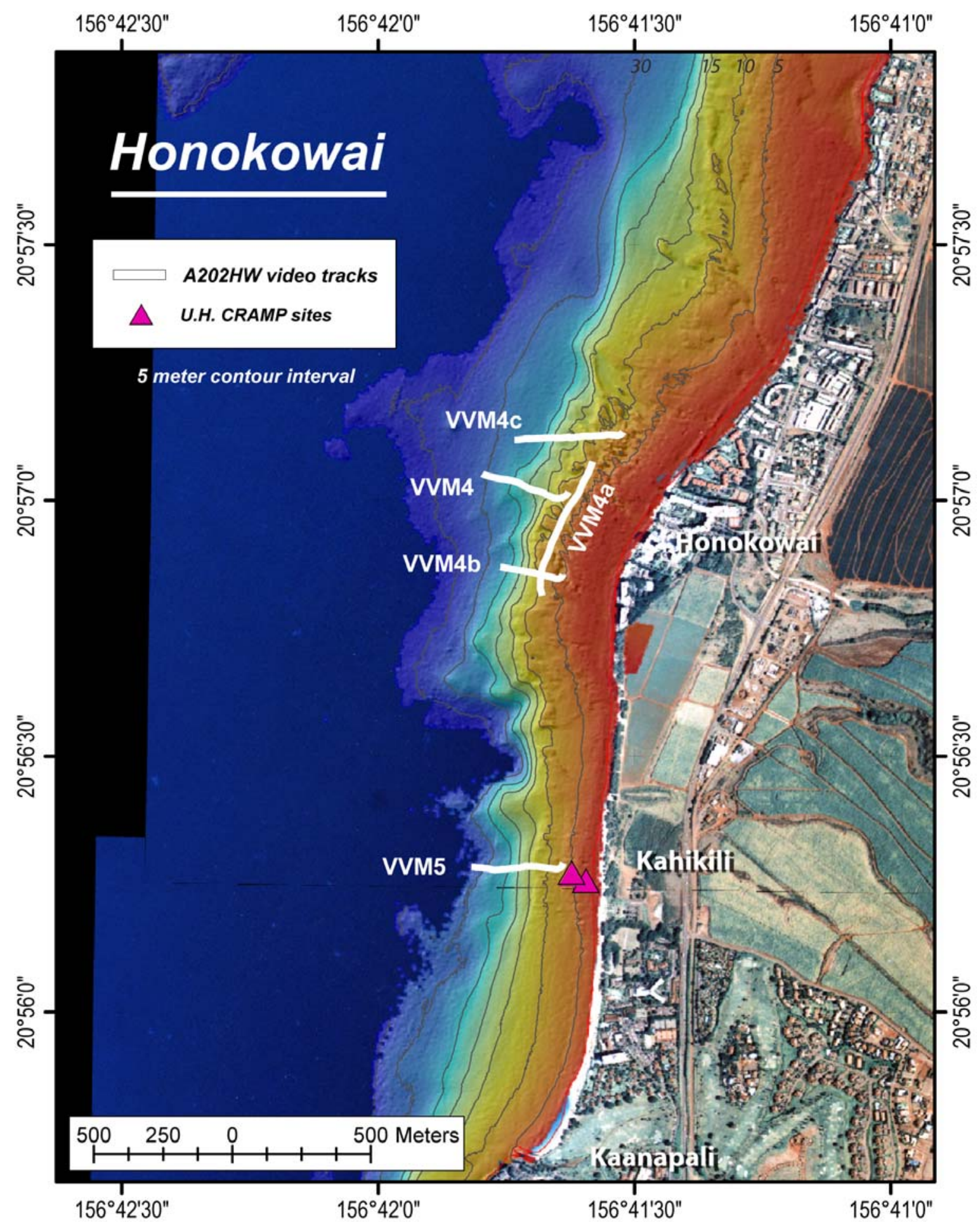

Figure 4.4 U.H. CRAMP sites and underwater video trackline locations overlain on a composite image (color vertical aerial photography and SHOALS lidar bathymetry) within the Honokowai region off the west coast of Maui. 


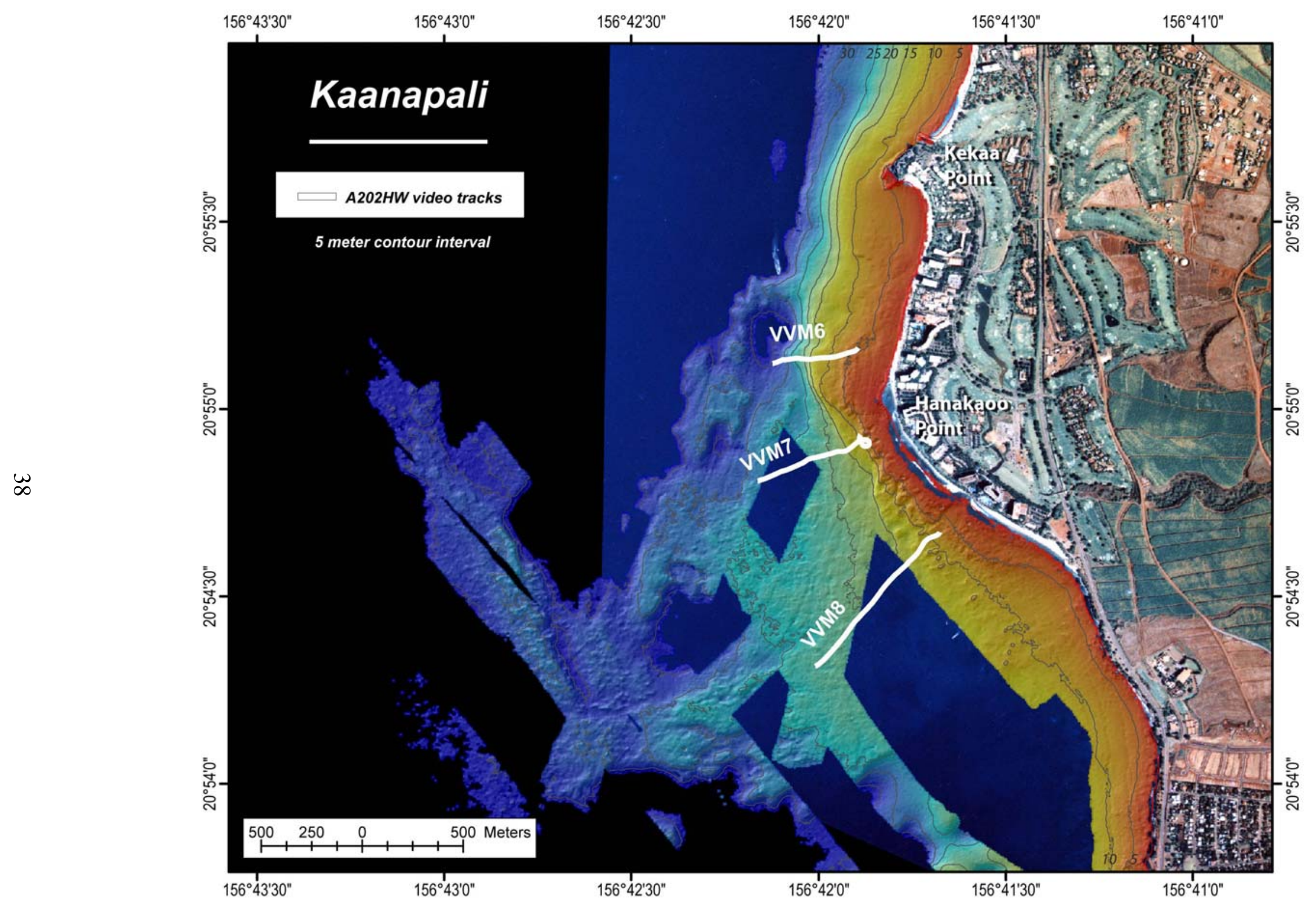

Figure 4.5 Underwater video trackline locations overlain on a composite image (color vertical aerial photography and SHOALS lidar bathymetry) within the Kaanapali reqion off the west coast of Maui. 


\section{Lahaina}

Two shore parallel and three shore normal transects were collected in the Lahaina region, between Lahaina and Launiupoko Point (Figure 4.6). Between Lahaina and Launiupoko, several extensive (1-2 km alongshore), shallow $(<10 \mathrm{~m})$ reef complexes are mapped on the NOS charts. Very little coral reef was observed in the area, however, transects typically started in water depths greater than $10 \mathrm{~m}$. High boat traffic in the area prevented surveying this area in greater detail and the individual transect may not be representative of the area. More work is probably warranted in this region, especially around Lahaina, because of the large reef tract and the potential anthropogenic pressures on the reef.

Line VVM9 off the north side of Lahaina showed large amounts of turf algae, degraded coral, and many urchins. There was no good coral coverage in either type or quality. Video cover started in more than $10 \mathrm{~m}$ of water and the nearshore, shallow reef platform was missed. This transect may not be representative of the area.

Line VVM10, near the Puamana CRAMP site, was primarily a sand flat covered with algae (Halimeda sp.?) and poor coral cover offshore. The CRAMP site was too shallow to image, and was located about $20 \mathrm{~m}$ north of the start of the line.

Line VVM11, off Launiupoko Pt. showed a benthic environment not observed to the north. In the video, it appeared to be a muddy substrate colonized with turf algae and sparse Pocillopora meandrina transitioning first to uncolonized, rippled sand and then to Halimeda sp. populated sand flats. There is a muddy, 2-3 m high, eroding cliff exposed on the shoreline adjacent to this site. An attempt was made to two days later to re-occupy the site and collect a sample. Some discussion ensued whether or not the sample collected was of the substrate observed previously and described above. In any event, it was fossil reef covered with turf algae - no mud was present. 


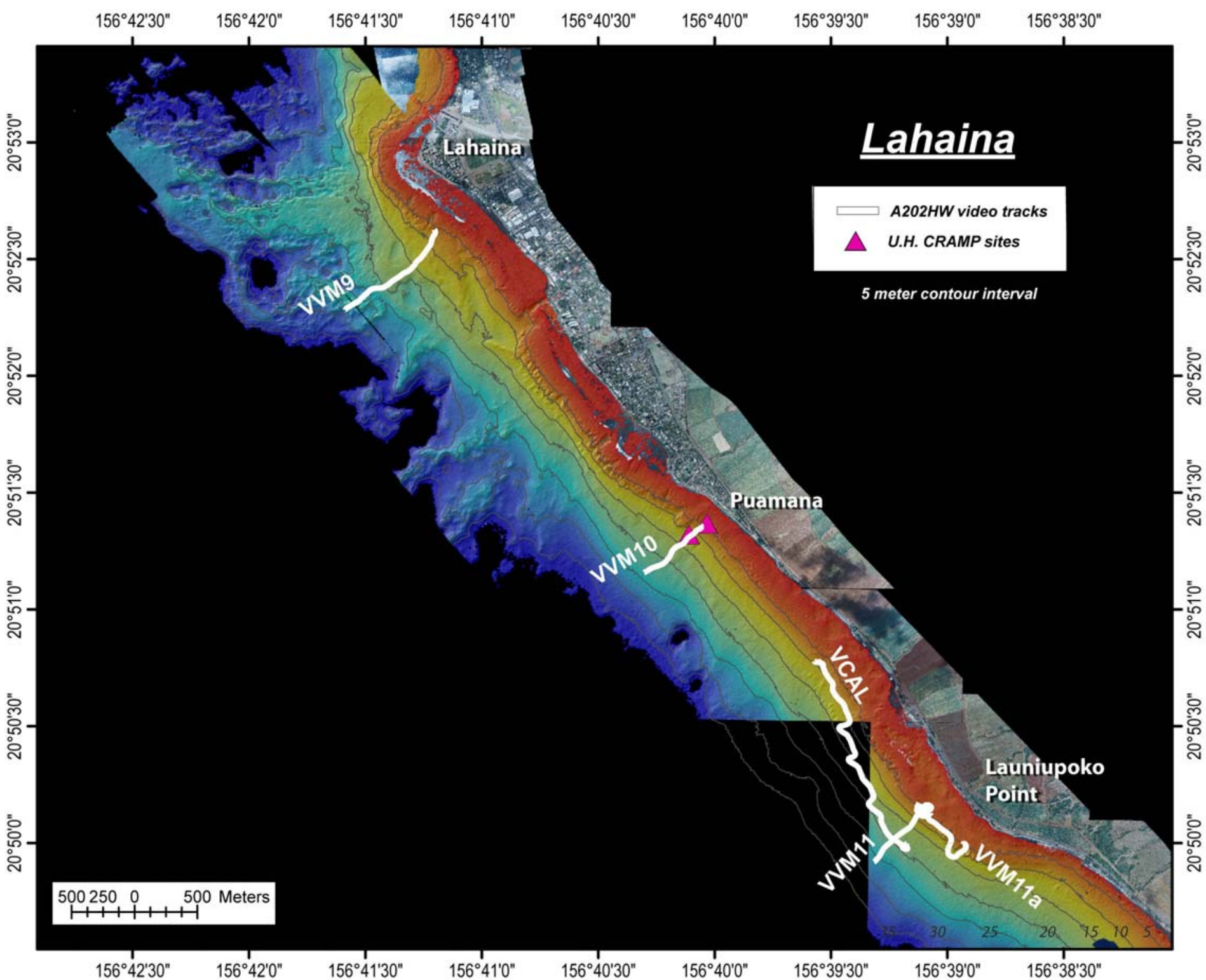

Figure 4.6 U.H. CRAMP sites and underwater video trackline locations overlain on a composite image (color vertical aerial photography and SHOALS lidar bathymetrv) within the Lahaina reqion off the west coast of Maui. 


\section{Olowalu}

One shore parallel and five shore normal transects were collected in the Olowalu region, between Olowalu and Papawai Point (Figure 4.7). Olowalu sits atop an alluvial fan and numerous steep gulches incise the upland mountains and reach the coastal terrace in this region. The island's largest and most well-developed fringing reef is also found in this area. Typically a very low energy environment, the day it was surveyed was fairly windy and choppy causing the water to be quite turbid.

Limited coral reef was observed off the north side of the pier at Olowalu and Hekili Point (VVM12). The reef quickly transitioned to thick Halimeda sp. beds offshore. Line 12a was added just south of pier to better define the coral communities on the northwest-southeast trending portion of reef flat surrounding Hekili Point (compared to the southwest-northeast trending reef southeast of the point). Video along line VVM12a showed an extensive fringing reef characterized by high coral cover and a sharp transition to sand and rubble with Halimeda sp. offshore.

Off the south side of Hekili Pt. the reef tract changes orientation from northwest-southeast to southwest-northeast trending reef front. Here an extensive reef flat with 90-100\% coral cover was observed, extending past the SHOALS bathymetry and the end of the cable. SHOALS data show this to be an area of very irregular bathymetry, with spur-and-groove and "blue hole" morphology.

Line VVM14, is located about $2 \mathrm{~km}$ southeast of VVM13 in an area where the sea floor bathymetry is much smoother. The bottom was similar to VVM13 with highly colonized spur-and-groove morphology and coral cover out to at least $40 \mathrm{~m}$ water depth.

Line VVM15 is located just south of Papawai Point. Here good coral cover was observed inshore, but, because of turbid water and a steep offshore gradient, it was difficult to observe much offshore. An attempt was made to cross a series of topographic highs to the east of VVM15 (VVM15a). High seas, turbid water, and boat traffic prevented ideal coverage, however, it appeared that there was potentially $100 \%$ coral cover along the entire transect, even in the deep water between the mounds. Thorne (2001) maps coral coverage in pinnacles and coves throughout the area between here and Maalaea Harbor to the east. 


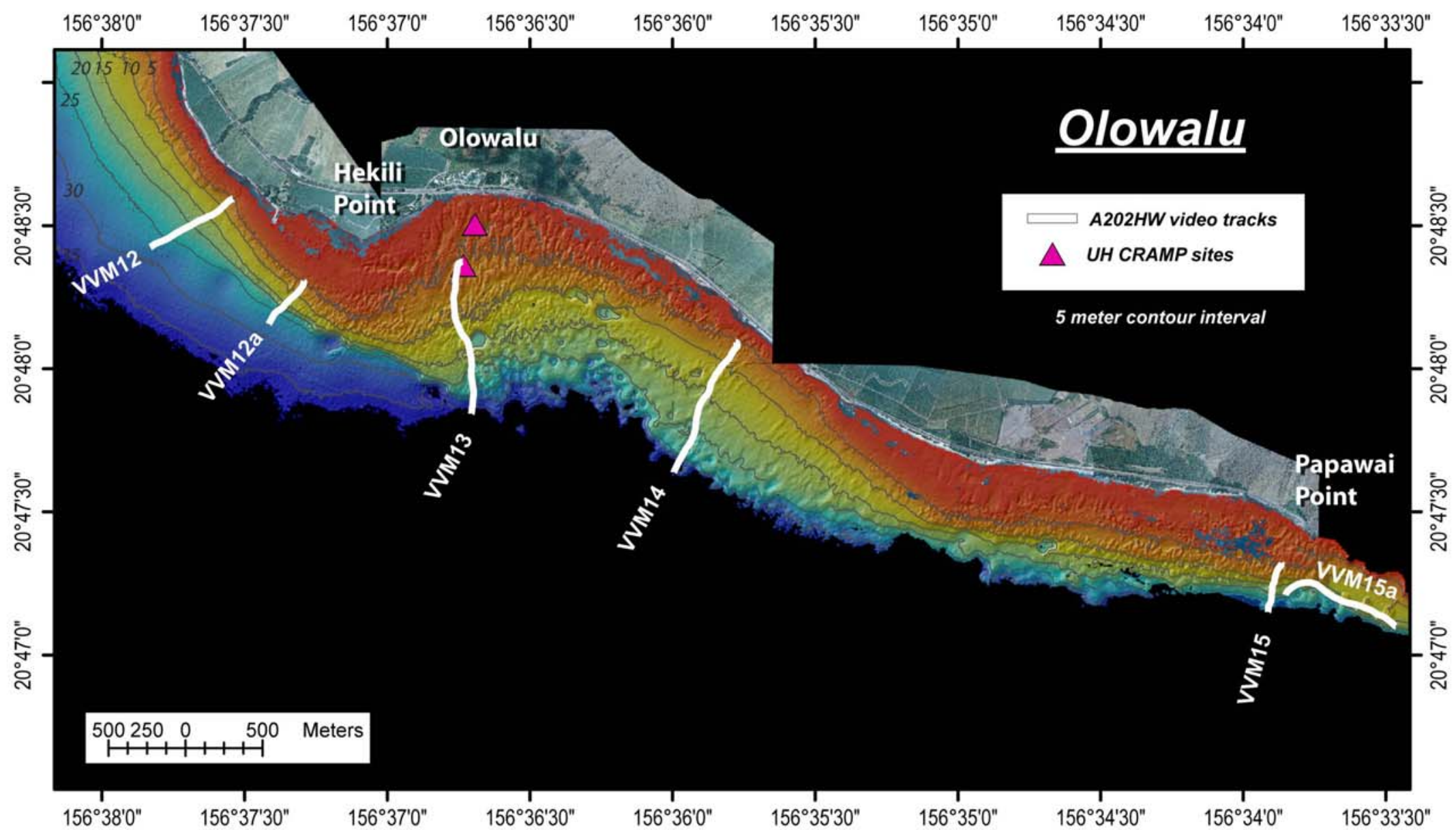

Figure 4.7 U.H. CRAMP sites and underwater video trackline locations overlain on a composite image (color vertical aerial photography and SHOALS lidar bathymetry) within the Olowalu reqion off the west coast of Maui. 


\section{Kihei}

One shore parallel and five shore normal transects were collected in the Kihei region, between Maalaea Harbor and Keawakapu (Figures 4.8 and 4.9). The area between Maalaea Bay to just south of Keawakapu is characterized by discontinuous shallow reef flat close to shore, transitioning to sand flats, sometimes with algae, and then to coral covered, shore sub-parallel ridges offshore. The ridges show very high, very healthy coral cover. Little, if any, coral reef has been mapped previously in this offshore area and no published information describing this area was found by the author. The NOAA benthic habitat maps do not identify coral reef in this area. SHOALS bathymetry shows well the fairly high relief bathymetry offshore, with ridges and platforms in depths greater than about $15 \mathrm{~m}$. This morphology continues south to about $400 \mathrm{~m}$ south of Keawakapu (see description below for VVM20a). The bathymetric highs offshore are likely entirely covered with healthy dense coral. The presence of near shore reef may not have been detected due to the inability to collect video in water depths less than about $10 \mathrm{~m}$.

The water directly off the breakwater at Maalaea Harbor (VVM17), one of the CRAMP sites, was too murky to determine bottom type. However, three pinnacles located between 0.5 and $1 \mathrm{~km}$ offshore, between about 12 and 15 m water depths, were covered with nearly $100 \%$ live coral.

Continuing around the Maalaea embayment to site VVM16, just south of the Kihei pier, the water continued to be murky. Close to shore the bottom type was predominantly sand. In water depths greater than about $15 \mathrm{~m}$ and about $1.5 \mathrm{~km}$ offshore, dense coral cover was observed on numerous mounds and pinnacles.

NOS navigation charts show a fairly extensive shallow reef platform offshore of central Kihei, between Kalepolepo and Kalama Park. A transect across the northern end of this platform, was collected (VVM18). The transect started along seaward edge of the platform and showed a nearshore colonized reef platform transitioning to aggregate coral/spur-and-groove, Halimeda sp. in sand, and finally poorly (?) colonized pavement offshore.

Line VVM19, at the southern boundary of the same reef complex, showed mostly sand close to shore, however, several hundreds of meters of 90-100\% coral cover on the offshore ridges were 
found, transitioning to coral rubble and algae about $32 \mathrm{~m}$ and the seaward end of SHOALS coverage.

Transect VVM20, off the north side of Keawakapu, showed transitions similar to VVM19, with sand inshore transitioning to $90-100 \%$ coral cover on the offshore ridges.

At the next site south (VVM21), off Wailea Point, the benthic environment changes dramatically (as described in the next section), indicating a fundamental transition in bottom type and coral cover somewhere between Keawakapu and Wailea. Unfortunately, the SHOALS bathymetry in this transition zone is sparse. Bathymetric contours on NOS charts show that the offshore slope steepens dramatically south of Keawakapu. Line VVM20a was collected to define this boundary and suggests the transition is about $400 \mathrm{~m}$ south of VVM20. Preliminary NOAA Benthic Habitat maps located this transition about $700 \mathrm{~m}$ to the south. 


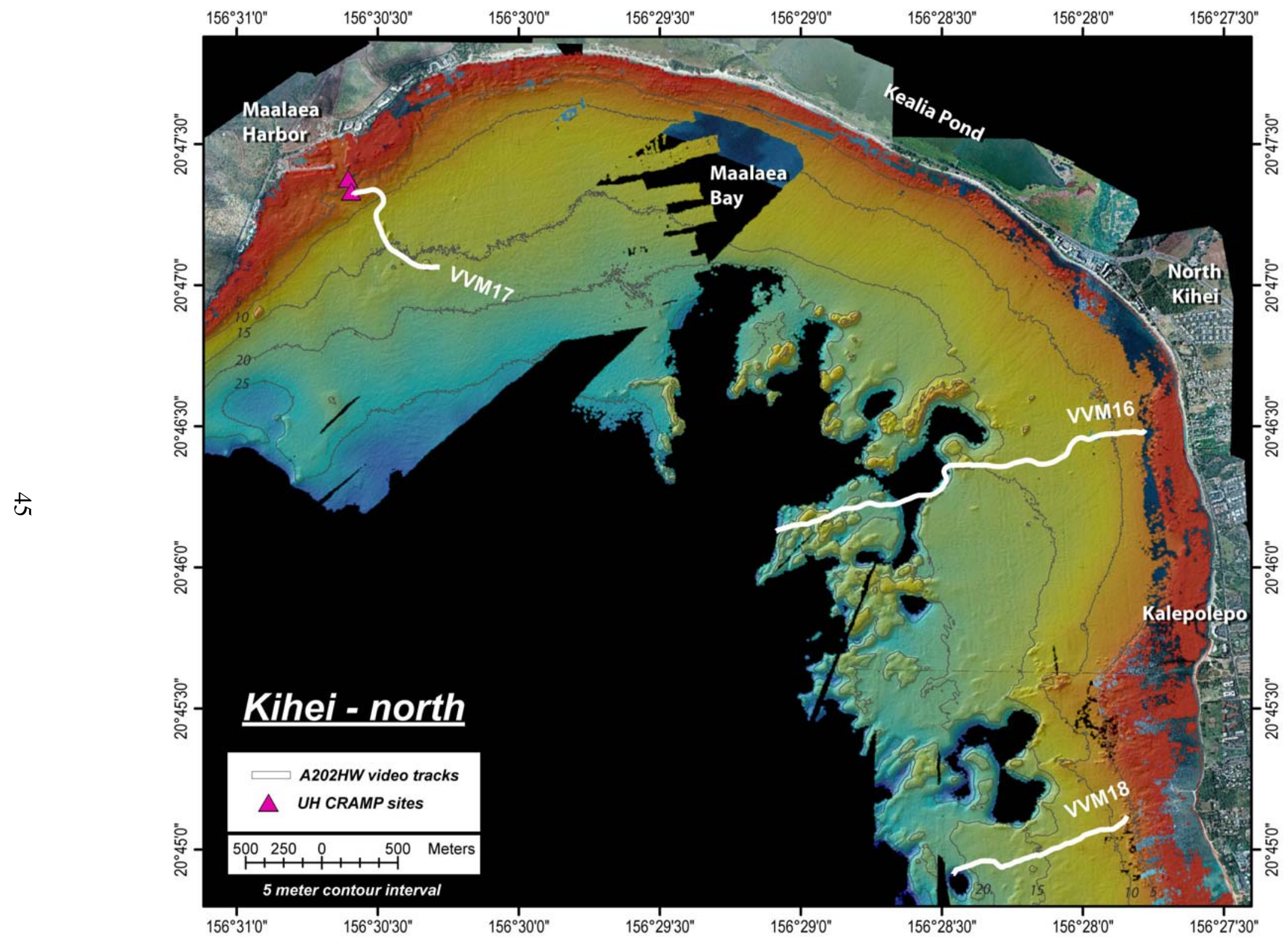

Figure 4.8 Map showing SHOALS lidar bathymetry, aerial photography, and the locations of the U.H. CRAMP sites and video transects collected in the north Kihei region off the west coast of Maui. 


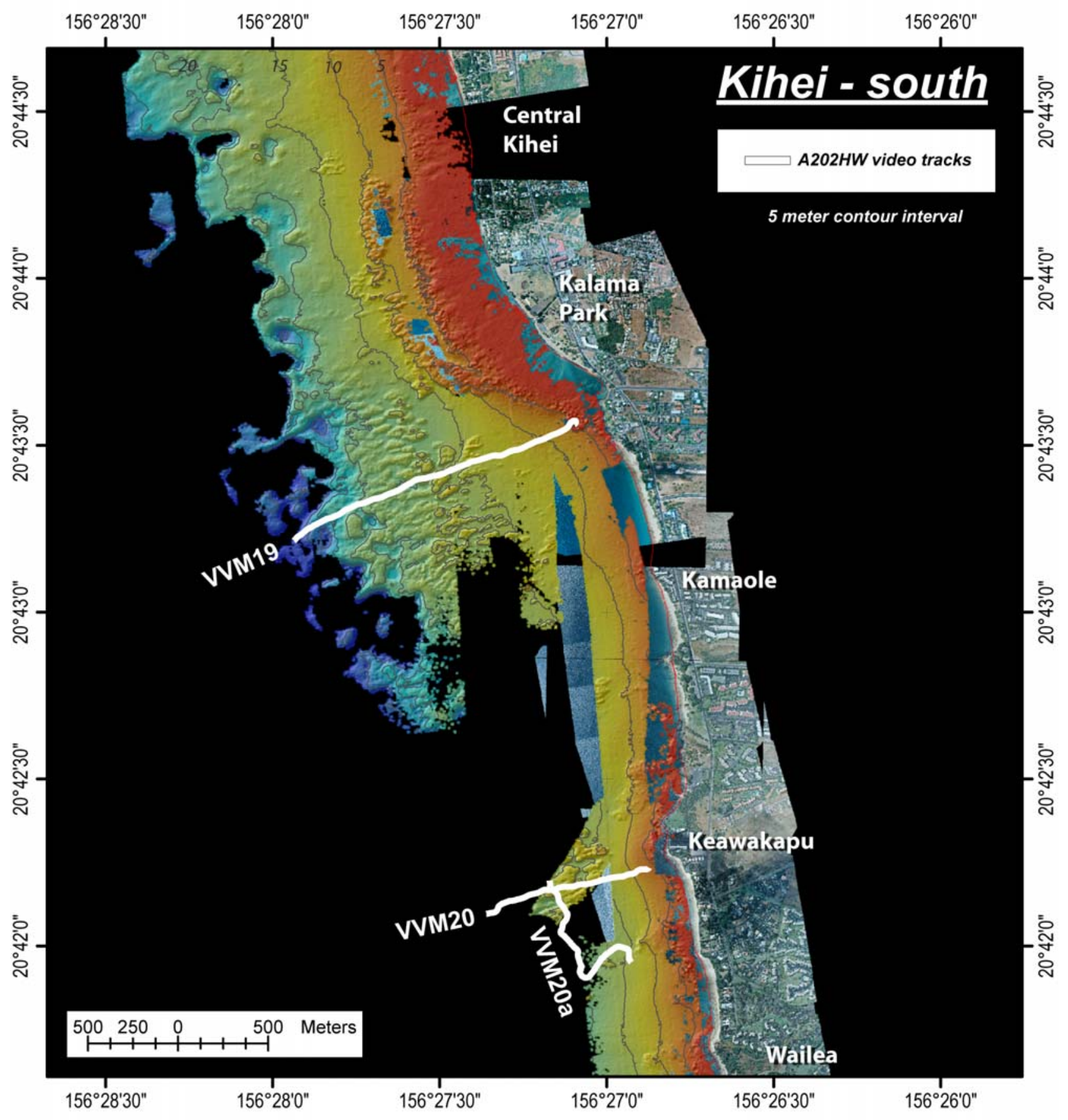

Figure 4.9 Map showing SHOALS lidar bathymetry, aerial photography, and video transects collected in the south Kihei region off the west coast of Maui. 


\section{Wailea}

Three shore normal transects were collected in the Wailea Region, between Wailea Point and Puu Olai (Figure 4.10). A distinct transition in offshore morphology and bottom type was observed between the Kihei and Wailea regions, as discussed above. The Wailea area is characterized by dense coral cover in embayments close to shore, transitioning to macroalgae-covered sand flats offshore.

The transect off Wailea Point (VVM21), a rocky volcanic headland, showed high coral cover in the nearshore, transitioning quickly to extensive beds of thick green and brown macroalgae-covered sands offshore. This algae was 'thick' and of a different type than observed to the north (Clodophora sp.??).

Line VVM22, off Nuhuna Point, the volcanic headland just north of Makena showed a similar, fairly abrupt transition from healthy, dense coral nearshore to algae covered sand flats and possible uncolonized pavement offshore. Similarly, along the northern base of Puu Olai (VVM23), beautiful dense coral inshore transitioned to pavement then macroalgae-covered sands in deeper water. 


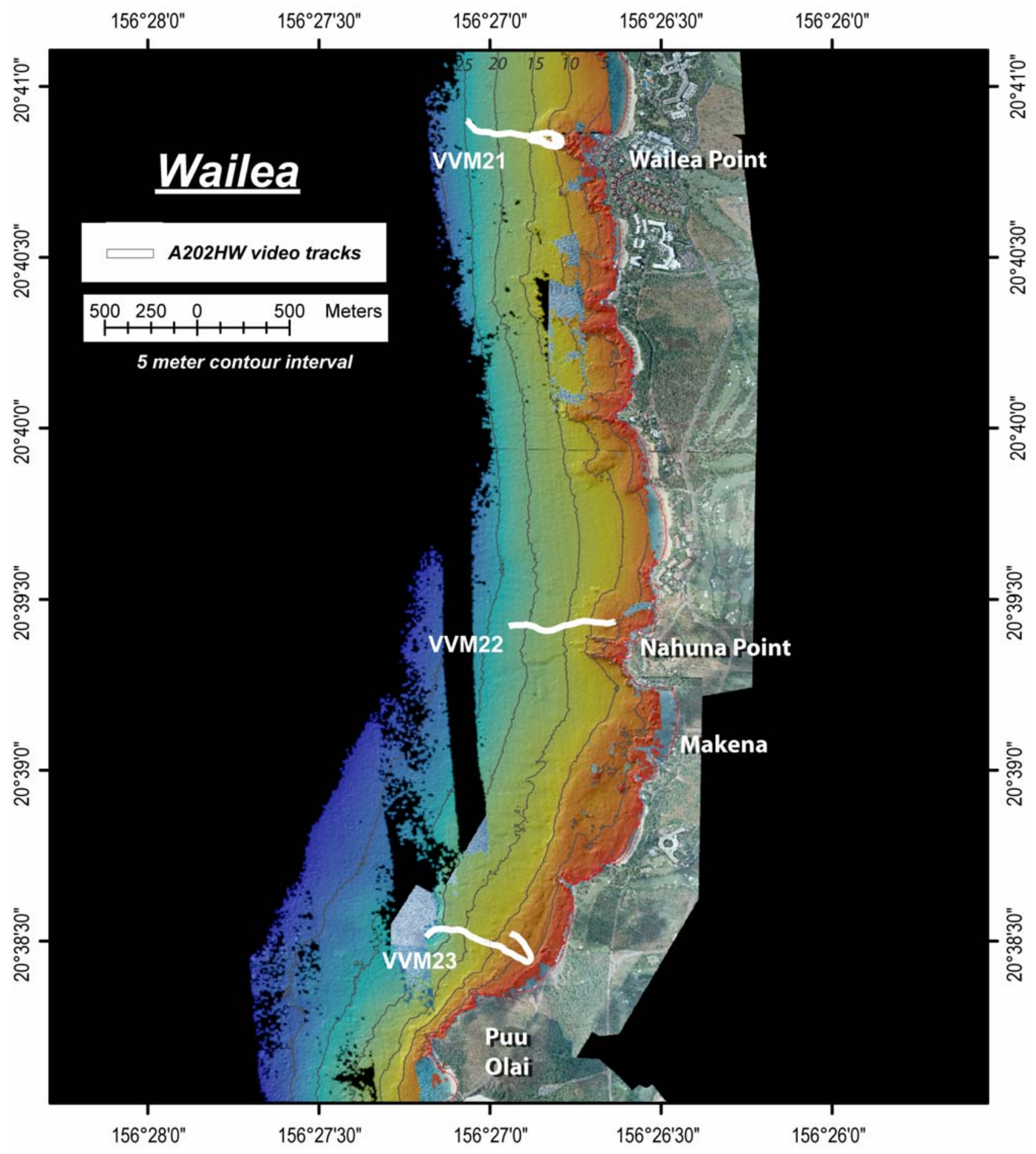

Figure 4.10 Map showing SHOALS lidar bathymetry, aerial photography, and video transects collected in the Wailea region off the west coast of Maui. 


\section{Ahihi-Kinau Preserve}

One shore parallel and six shore normal transects were collected in the Ahihi-Kinau Preserve, between Ahihi Bay and Cape Hanamanioa (Figure 4.11). This area is characterized by very high coral cover in water depths less than $10 \mathrm{~m}$, transitioning to partially colonized volcanic pavement with rubble and sand flats, with or without Halimeda sp., in deeper water. The area is geologically young, with the coral colonizing volcanic flows presumed to have erupted from Haleakala between A.D. 1490 and 1600 (U.S. Geological Survey, 1999). This area is one of the few areas outside the Northwest Hawaiian Islands where 'naïve fish behavior' has been observed (Besty Gagne, Department of Land and Natural Resources (DLNR), personal communication 2002). During this survey, little coral reef habitat or fish were observed.

Line VVM24 on the north side of Ahihi Bay showed some live coral cover close to shore transitioning to sparse, isolated coral seaward of the first ledge, alternating with fields of rippled, uncolonized sand and beds of Halimeda sp..

Line VVM25, off the north end of Cape Kinau showed both live and dead coral reef continuing offshore to a sharp transition with sand and Halimeda sp. over a ledge/sharp drop.

Line VVM26, off of Kanahena Point showed coral covered basalt with very high rugosity and high coral cover.

Line VVM27, off of Kalaeloa showed high coral cover close to shore, decreasing offshore to Halimeda sp. beds in deeper water (similar to VVM26).

Line VVM28, within La Peruse Bay showed mostly sand and rubble with a coral covered linear ridge in middle of bay.

Line VVM29, off the southern end of Cape Hanamanioa showed a wide, shallow reef flat with good coral cover. 
Line VVM30, was a shore parallel line from Cape Hanamanioa to just north of Kanahena Point. Some good coral cover was observed in less than $10 \mathrm{~m}$ of water. The video imagery acquired along this transect is less than ideal because of high seas and turbid water during data collection. 


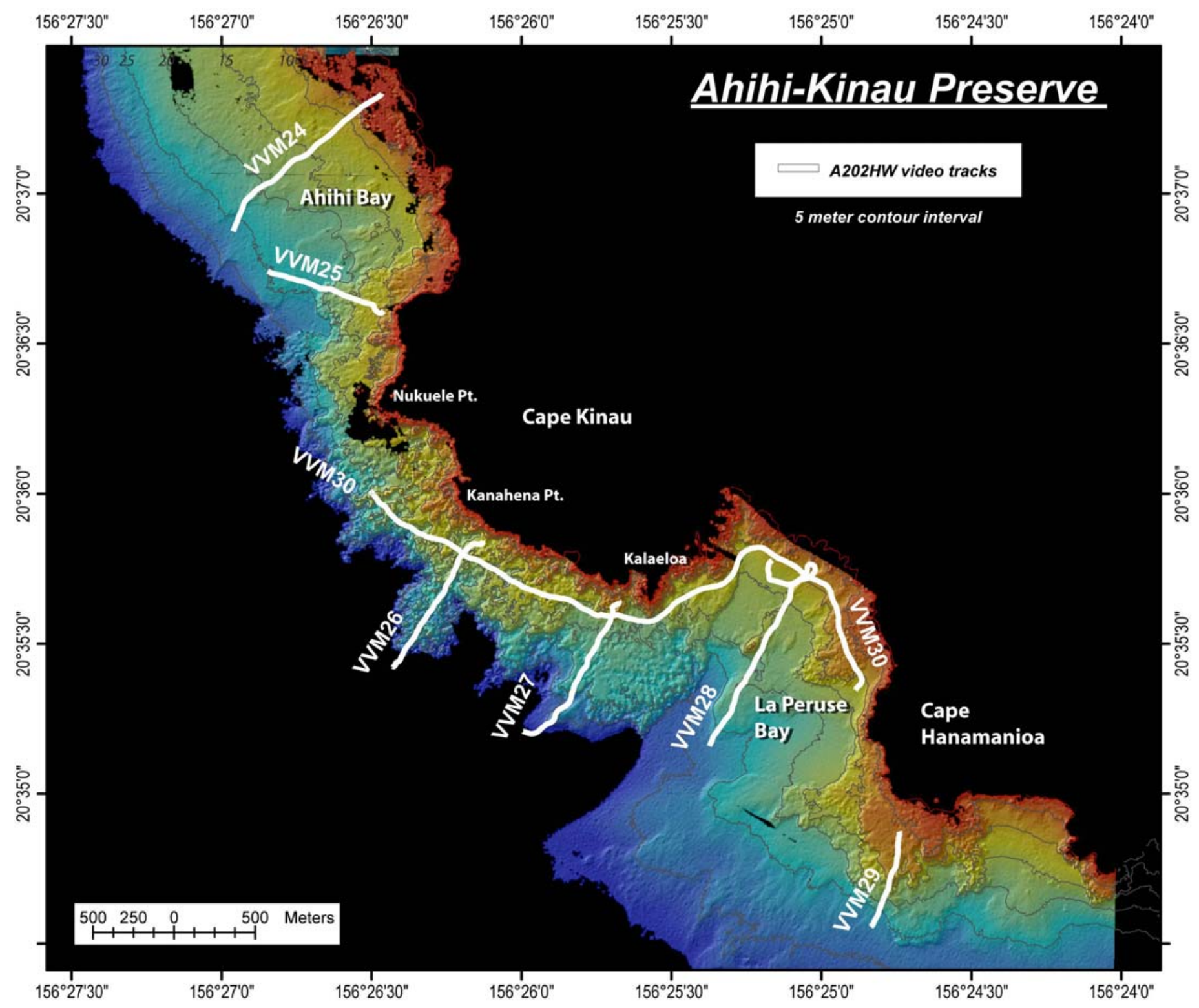

Figure 4.11 Map showing SHOALS lidar bathymetry and location of video transects collected in the Ahihi-Kinau region off the west coast of Maui. 
Table 4.1. Underwater video transect summary for western Maui.

\begin{tabular}{|c|c|c|}
\hline Line* & Description & Length (km) \\
\hline VVM 1 & Shore normal transect off the south end of Napili Bay & 0.71 \\
\hline VVM2 & Shore normal transect off the south end of Kaia Pt. across Kahana tripod site & 0.67 \\
\hline VVM2a & Shore parallel transect along the $10 \mathrm{~m}$ contour, across Kahana tripod site & 1.18 \\
\hline VVM3 & Shore normal transect near Kapua & 0.49 \\
\hline VVM4 & Shore normal transect off Honokowai Point & 0.32 \\
\hline VVM4a & Shore parallel transect across VVM4, along $\sim 10 \mathrm{~m}$ contour & 0.52 \\
\hline VVM4b & Shore normal transect about $300 \mathrm{~m}$ south of VVM4 & 0.22 \\
\hline VVM4c & Shore normal transect about 500 m north of VVM4 & 0.38 \\
\hline VVM5 & Shore normal transect offshore Kahikili CRAMP site & 0.33 \\
\hline VVM6 & Shore normal transect off the north side of Hanakaoo Point & 0.41 \\
\hline VVM7 & Shore normal transect off the middle of Hanakaoo Point & 0.67 \\
\hline VVM8 & Shore normal transect off the south side of Hanakaoo Point & 0.89 \\
\hline VVM9 & Shore normal transect off Lahaina, between Puunoa and the harbor & 0.97 \\
\hline VVM10 & Shore normal transect south of Lahaina at the Puamana CRAMP site & 0.59 \\
\hline VVM11 & Shore normal transect off Launiupoko Point & 0.58 \\
\hline VVM11a & Shore parallel transect across VVM11 & 0.74 \\
\hline VVM12a & Shore normal transect off Hekili Point; NW-SE trending reef platform & 0.36 \\
\hline VVM13 & Shore normal transect south of Hekili Point; NE-SW trending reef platform & 1.03 \\
\hline VVM14 & Shore normal transect off Ukumehame & 0.95 \\
\hline VVM15 & Shore normal transect off Manawaipueo Gulch & 0.33 \\
\hline VVM15a & Shore parallel transect across pinnacles just southeast of VVM15 & 0.78 \\
\hline VVM16 & Shore normal transect between Kihei Pier and Mapoina Park & 2.58 \\
\hline VVM17 & Shore normal transect off Maalaea Harbor CRAMP site & 0.92 \\
\hline VVM18 & Shore normal transect off the Maui Sunset & 1.22 \\
\hline VVM19 & Shore normal transect off the north end of Kamaole I Beach Park & 1.66 \\
\hline VVM20 & Shore normal transect off Keawakapu & 0.92 \\
\hline VVM20a & Shore parallel transect crossing VVM20 to define morphological transition & 1.02 \\
\hline VVM21 & Shore normal transect off Wailea & 0.93 \\
\hline VVM22 & Shore normal transect off Makena & 0.56 \\
\hline VVM23 & Shore normal transect at the base of the northern side of Puu Olai & 0.79 \\
\hline VVM24 & Shore normal transect through northern part of Ahihi Bay & 1.24 \\
\hline VVM25 & Shore normal transect off north side of Cape Kinau, near Ka Lae Mamane & 0.75 \\
\hline VVM26 & Shore normal transect off Cape Kinau, between Kanahena Pt. and Pohaku Paea & 0.99 \\
\hline VVM27 & Shore normal transect off southern side of Cape Kinau, near Kalaeloa & 1.07 \\
\hline VVM28 & Shore normal transect through center of La Peruse Bay & 1.78 \\
\hline VVM29 & Shore normal transect off Cape Hanamanioa & 0.62 \\
\hline \multirow[t]{2}{*}{ VVM30 } & $\begin{array}{l}\text { Shore parallel transect, approx. 30-40' water depth, between Cape Hanamanioa } \\
\text { and Kanahena Point }\end{array}$ & 1.95 \\
\hline & Total length surveyed $(\mathrm{km})$ & 32.12 \\
\hline
\end{tabular}

*Video data of transect lines VVM 1-30 are archived on tapes 17-22 and 25-27 (9). 
TABLE 4.2 UTC, Start (SOL) and End (EOL) locations of survey transects.

\begin{tabular}{|c|c|c|c|c|c|c|c|}
\hline Line & UTC Time & titude & Longitude & Line & UTC Time & Latitude & Longitude \\
\hline & 20021842206600 & & & & 20021852012600 & & \\
\hline & 20021842214300 & & & & & & \\
\hline & & & & & & & \\
\hline & 20021842235200 & 0.985443 & & & 20021852051600 & & \\
\hline & & & & & & & \\
\hline & 20021842301300 & 20.980708 & & & 20021852115300 & & \\
\hline & & & & & & & \\
\hline & 20021842318100 & 20.970763 & & & & & \\
\hline & & & & & & & \\
\hline & 200218423 & & & & & & \\
\hline & & & & & & & \\
\hline & 200218423 & & & & & & \\
\hline & & & & & & & \\
\hline & & & & & & & \\
\hline & & & & & & & \\
\hline & & & & & & & \\
\hline & & & & & & & \\
\hline & & & & & & & \\
\hline & & & & & & & \\
\hline & & & & & & & \\
\hline & & & & & & & \\
\hline & & & & & & & \\
\hline & & & & & & & \\
\hline & & & & & & & \\
\hline & & & & & & & \\
\hline & & & & & & & \\
\hline & & & & & & & \\
\hline & & & & & & & \\
\hline & & & & & & & \\
\hline & & & & & & & \\
\hline 11a_SOL & 20021850247100 & 20.833273 & & & & & \\
\hline & 20021850254400 & & & & & & \\
\hline & 20021851712400 & 20.788665 & & & & & \\
\hline & 20021851724500 & & & 28_EOL & & & -156.422888 \\
\hline & & & & & & & \\
\hline & & & & & & & \\
\hline & & & & & & & \\
\hline 1]_LUL & 20021851929200 & 20.720241 & -156.465598 & 30_EOL & 20021872002200 & 20.600150 & $-100.441 / 40$ \\
\hline
\end{tabular}

UTC time format is YYYYDDDHHMMSST (year, Julian_day, hour, minute, seconds, tenths)

Coordinates are decimal degrees, WGS84 


\section{$\underline{\text { References }}$}

Barnhardt, W.A., Richmond, B.M., Grossman, E.E., and Hart, P., 2003, Seismic stratigraphy of a mixed carbonate-siliciclastic environment: influence of antecedant topography and sea-level change at Molokai, Hawaii. Coastal Sediments”03, Clearwater Beach, Florida, May 18-23, 2003, Book of Abstracts p 205.

Brown, E.K., Cox, E., Jokiel, P.L., Rogers, S.K., Smith, W.R., Tissot, B., Coles, S.L., and Hultquist, J., 2004, Development of benthic sampling methods for the Coral Reef Assessment and Monitoring Program (CRAMP) in Hawai'i: Pacific Science, v. 58, no. 2, p. 145-158.

Calhoun, R.S. and Field, M.E., 2000, Beach and reef flat sediments along the south shore of Molokai, Hawaii. Proceedings Carbonate Beaches 2000, Key Largo, Florida, December 5-8, 2000, pp 163-171.

Coyne, M.S., Battista, T.A., Anderson, M., Waddell, J., Smith, W., Jokiel, P., Kendell, M.S. and Monaco, M.E. 2003. NOAA Technical Memorandum NOS NCCOS CCMA 152 (On-Line). Benthic Habitats of the Main Hawaiian Islands URL: http://biogeo.nos.noaa.gov/projects/mapping/pacific/.

Engels, Mary S., Fletcher, Charles H. III, Field, Michael E., Storlazzi, Curt D., Grossman, Eric E., Rooney, John J.B., Conger, Christopher L., and Glenn, Craig, 2004, Holocene reef accretion: Southwest Moloka'i, Hawai'i, U.S.A.: Journal of Sedimentary Research, v. 74, no. 2, p. 255-269.

Eversole, D. and Fletcher, C.H., 2003. Longshore sediment transport rates on a reef-fronted beach: field data and empirical models, Kaanapali Beach, Hawaii: Journal of Coastal Research, v. 19, p. 649-663.

Gibbs, A.E., Richmond, B.M., and Fletcher, C.H., 2002. Profile variation on Hawaiian carbonate beaches. In: Carbonate Beaches 2000, O.T. Magoon, L.L. Robbins, and L. Ewing, Eds. First International Symposium on Carbonate Sand Beaches. Dec. 5-8, 2002. Conference Proceedings, ASCE p. 99-110.

Jokiel, P.L., Brown E.K., Friedlander, A., Rogers, S.K., and Smith, W.R., 2004, Hawaii Coral Reef Assessment and Monitoring Program: spatial patterns and temporal dynamics in reef coral communities: Pacific Science, v. 58, no. 2, p. 159-174.

Logan, J.B., Field, M.E., and Chavez, P.S., in press, Views of a fringing coral reef, Moloka'i, Hawai'i: U.S. Geological Survey Scientific Investigations Map 2886

Storlazzi, C.D., Brown, E.K., Field, M.E., Rodgers, K., and Jokiel, P.L., 2005. A model for wave control on coral breakage and species distribution in the Hawaiian Islands. Coral Reefs, v. 24, p. 43-55.

Storlazzi, C.D. and Jaffe, B.E., 2003. Coastal Circulation and Sediment Dynamics along West Maui, Hawaii, PART I: Long-term measurements of currents, temperature, salinity and turbidity off Kahana, West Maui: 2001-2003. U.S. Geological Survey Open-File Report 03-482, 28 p. 
Storlazzi, C.D., Logan, J.B., and Field, M.E, 2003, Quantitative morphology of a fringing reef from high-resolution laser bathymetry: Southern Molokai, Hawaii: Geological Society of America Bulletin, v. 115, no. 11, p. 1344-1355.

Thorne, Chuck. 2001. The Divers' Guide to Maui. Maui Dive Guide, Hana HI. 80p.

U.S. Geological Survey, 1999. Youngest lava flows on East Maui probably older than A.D. 1790. Hawaiian Volcano Observatory website URL: http://hvo.wr.usgs.gov/volcanowatch/1999/99 09 09.html.

Wells, S.M. and Jenkins, M.D., 1988. Coral Reefs of the World. Volume 3: Central and Western Pacific. United Nations Environment Programme, International Union for Conservation of Nature and Natural Resources.

\section{$\underline{\text { Acknowledgements }}$}

We would like to thank the following people for their assistance with this project: Hank Chezar, Josh Logan, and Gerry Hatcher of the USGS, Cpt. Joe Reich, and Betsy Gagne of Hawaii DLNR. Very helpful reviews were provided by Curt Storlazzi and Susan Cochran-Marquez of the USGS. 


\section{Appendix I}

\section{A-2-02-HW: Cruise summary}

Vessel: AlyceC, Joe Reich Captain

Dates: 25-Jun-02 to 11-Jul-02

\section{Oahu}

Chief: Grossman

Crew: Hank Chezar, Eric Grossman, Gerry Hatcher

Dates: 25-Jun-02 to 28-Jun-02

Tapes: $1-9$ (9)

Lines: OVHM $1-14$

\section{Molokai}

Chief: Richmond

Crew: Hank Chezar, Ann Gibbs, Eric Grossman, Gerry Hatcher

Dates: 30-Jun-02 to 02-Jul-02

Tapes: $10-16(7)$

Lines: MVM 1-16

\section{Maui}

Chief: Gibbs

Crew: Eric Grossman, Bruce Richmond

Dates: 03-Jul-02 to 06-Jul-02

Tapes: $17-27$ (11)

Lines VVM 1-30

Molokai (pc_Molokai)

Chief: Pat Chavez

Crew: Ann Gibbs, Will Smith

Dates 08-Jul-02 to 11-Jul-02

Tapes: $28-37$ (10)

Points: $1-365$ 


\section{Appendix II}

Summary of Digital 8 video tapes, location, dates, and lines collected

\begin{tabular}{|c|c|c|c|c|c|}
\hline Island & Chief & Date & Index & Tape & Lines \\
\hline \multirow[t]{9}{*}{ Oahu } & Grossman & 26-Jun-02 & A202HW_TAPE1_26Jun02 & 1 & OHVM 2, 3, 3a, 3b \\
\hline & & 26-Jun-02 & A202HW_TAPE2_26Jun02 & 2 & OHVM 6,7 \\
\hline & & 27-Jun-02 & A202HW_TAPE3_27Jun02 & 3 & OHVM 1,5,5a \\
\hline & & 27-Jun-02 & A202HW_TAPE4_27Jun02 & 4 & OHVM 4 \\
\hline & & 27-Jun-02 & A202HW_TAPE5_27Jun02 & 5 & OHVM 13 \\
\hline & & 27-Jun-02 & A202HW_TAPE6_27Jun02 & 6 & OHVM 12, 11 \\
\hline & & 27-Jun-02 & A202HW_TAPE7_27Jun02 & 7 & OHVM 11(cont.),10 \\
\hline & & 28-Jun-02 & A202HW_TAPE8_28Jun02 & 8 & OHVM 8,9 \\
\hline & & 28-Jun-02 & A202HW_TAPE9_28Jun02 & 9 & OHVM 14 \\
\hline \multirow[t]{7}{*}{ Molokai } & Richmond & 30-Jun-02 & A202HW_TAPE10_30Jun02 & 10 & MVM 1,1a,1b,2,3 \\
\hline & & 30-Jun-02 & A202HW_TAPE11_30Jun02 & 11 & MVM 4,5,5a \\
\hline & & 1-Jul-02 & A202HW_TAPE12_01Jul02 & 12 & MVM 6,6a,7,7a,8,8a \\
\hline & & 1-Jul-02 & A202HW_TAPE13_01Jul02 & 13 & MVM 9,10,11,12,13 \\
\hline & & 2-Jul-02 & A202HW_TAPE14_02Jul02 & 14 & MVM 5a-2,14 \\
\hline & & 2-Jul-02 & A202HW_TAPE15_02Jul02 & 15 & MVM 14 \\
\hline & & 2-Jul-02 & A202HW_TAPE16_02Jul02 & 16 & MVM 15,16 \\
\hline \multirow[t]{6}{*}{ Maui } & Gibbs & 3-Jul-02 & A202HW_TAPE17_03Jul02 & 17 & VVM 1,2,2a,3 \\
\hline & & 3-Jul-02 & A202HW_TAPE18_03Jul02 & 18 & VVM 4,4a,4b,4c,5,6,7,8 \\
\hline & & 3-Jul-02 & A202HW_TAPE19_03Jul02 & 19 & VVM 9,10,11,11a \\
\hline & & 4-Jul-02 & A202HW_TAPE20_04Jul02 & 20 & VVM 17,16 \\
\hline & & 4-Jul-02 & A202HW_TAPE21_04Jul02 & 21 & VVM 19,20,21 \\
\hline & & 4-Jul-02 & A202HW_TAPE22_04JulO2 & 22 & VVM 22,23,20a, 18 \\
\hline Maui Nui & Grossman & 5-Jul-02 & A202HW_TAPE23_05Jul02 & 23 & VMN 1,2,3,4 \\
\hline \multirow[t]{4}{*}{ Maui } & Gibbs & 5-Jul-02 & A202HW_TAPE24_05Jul02 & 24 & VCAL1 \\
\hline & & 5-Jul-02 & A202HW_TAPE25_05Jul02 & 25 & VVM 12,12a,13,14,15,15a \\
\hline & & 6-Jul-02 & A202HW_TAPE26_06Jul02 & 26 & VVM 24,25,26,27 \\
\hline & & 6-Jul-02 & A202HW_TAPE27_06Jul02 & 27 & VVM 28,29,30 \\
\hline \multirow[t]{10}{*}{ Molokai } & Chavez & 8-Jul-02 & A202HW_TAPE28_08Jul02 & 28 & Points 1-46 \\
\hline & & 8-Jul-02 & A202HW_TAPE29_08Jul02 & 29 & Points 47-78 \\
\hline & & 8-Jul-02 & A202HW_TAPE30_08Jul02 & 30 & Points 79-105 \\
\hline & & 9-Jul-02 & A202HW_TAPE31_09Jul02 & 31 & Points 107-162 \\
\hline & & 9-Jul-02 & A202HW_TAPE32_09Jul02 & 32 & Points 163-205 \\
\hline & & 10-Jul-02 & A202HW_TAPE33_10Jul02 & 33 & Points 206-248 \\
\hline & & 10-Jul-02 & A202HW_TAPE34_10Jul02 & 34 & Points 249-295 \\
\hline & & 10-Jul-02 & A202HW_TAPE35_10Jul02 & 35 & Points 296-301 \\
\hline & & 11-Jul-02 & A202HW_TAPE36_11Jul02 & 36 & Points 302-340 \\
\hline & & 11-Jul-02 & A202HW TAPE37 11Jul02 & 37 & Points 341-365 \\
\hline
\end{tabular}

